\title{
Click Assembly of Dye-Functionalized Octasilsesquioxanes for Highly Efficient and Photostable Photonic Systems
}

\author{
M. Eugenia Pérez-Ojeda, ${ }^{[a]}$ Beatriz Trastoy, ${ }^{[b]}$ Íñigo López-Arbeloa, ${ }^{[c]}$ Jorge Bañuelos, ${ }^{[c]}$ Ángel \\ Costela, ${ }^{[\mathrm{a}]}$ Inmaculada García-Moreno, ${ }^{*[\mathrm{a}]}$ and Jose Luis Chiara ${ }^{*[\mathrm{~b}]}$
}

Dedicated to the memory of Professor Roberto Sastre

\begin{abstract}
New hybrid organicinorganic dyes based on an azidefunctionalized octasilsesquioxane (POSS) as inorganic part and a 4,4difluoro-4-bora-3a,4a-diaza-s-indacene (BDP) chromophore as the organic component have been synthesized by copper(I)-catalyzed 1,3-dipolar cycloaddition of azides to alkynes. We have studied the effect of the linkage group of BDP to the POSS unit and the degree of functionalization of this inorganic core on the optical properties by comparison with model dyes. The high fluorescence ability of the BDP dye is preserved in spite of the linked
\end{abstract}

chain at its meso position and even after attaching one BDP to the POSS core. The laser action of the new dyes has been analyzed under transversal pumping at $532 \mathrm{~nm}$ in both liquid phase and when incorporated into solid polymeric matrices. The new hybrid dye exhibits high lasing efficiency of up to $56 \%$ with high photostability, with its laser output remaining at the initial value after $4 \times 10^{5}$ pump pulses in the same position of the sample at 30 $\mathrm{Hz}$ repetition rate. Nonetheless, the functionalization of the POSS core with eight fluorophores leads to dye aggregation, as quantum mechanics simulation reveals, worsening the optical properties and extinguishing the laser action. The new hybrid systems based on dye-linked POSS nanoparticles opens up the possibility of using these new photonic materials as alternative sources for optoelectronic devices, competing with dendronized or grafted polymers.

\section{Keywords: azides • silsesquioxanes $\bullet$ click chemistry $\bullet$ dye/pigments $\bullet$ hybrids}

\section{Introduction}

[a] M. E. Pérez-Ojeda, Prof. Dr. A. Costela, Prof. Dr. I. García-Moreno Instituto Química-Física "Rocasolano", C.S.I.C.

Serrano 119, E-28006 Madrid, Spain Fax: (+) 34-915642431

E-mail: i.garcia-moreno@iqfr.csic.es

[b] B. Trastoy, Dr. J. L. Chiara

Instituto de Química Orgánica General, C.S.I.C.

Juan de la Cierva 3, E-28006 Madrid, Spain

Fax: (+) 34-915644853

E-mail: jl.chiara@iqog.csic.es

[c] Prof. Dr. I. López Arbeloa, Dr. J. Bañuelos

Departamento de Química Física

Universidad del País Vasco-EHU

Facultad de Ciencias y Tecnología

Apartado 644, E-48080-Bilbao, Spain

Fax: (+) 34-946013500

E-mail: inigo.lopezarbeloa@ehu.es

Supporting information for this article is available on the WWW under http://www.chemeurj.org/ or from the author.
Fully condensed polyhedral oligosilsesquioxanes (POSS) are unique nanometer-sized hybrid inorganic-organic materials of chemical composition $\left(\mathrm{RSiO}_{1.5}\right)_{\mathrm{n}}$, which can be readily synthesized by hydrolytic condensation of trifunctional organosilicon monomers $\mathrm{RSiX}_{3}\left(\mathrm{R}=\right.$ organic group; $\mathrm{X}=$ halogen or alkoxide group) ${ }^{[1]}$ Thanks to their rigid inorganic core, POSS are endowed with a considerable chemical and thermal stability that can be channeled to their pendant organic groups.

POSS nanoparticles have lead to novel applications in photonics and electronic devices, ${ }^{[2]}$ enhancing significantly the thermal, mechanical and physical properties of the final materials and opening the challenge to synthesize new luminescent hybrid matrices with optoelectronic properties comparable to dendronized or grafted conjugated polymers. ${ }^{[3]}$ POSS nanoparticles can be dispersed at a molecular level $(0.5-5 \mathrm{~nm})^{[4]}$ and, because of their synthetically well-controlled functionalization, can be incorporated into polymers by different polymerization techniques with minimal processing disruption. ${ }^{[5]}$ This excellent dispersion at molecular scale and the copolymerization with organic monomers prevents phase separation assuring the macroscopical homogeneity of the resultant 
materials. ${ }^{[6]}$ In this way, new optical hybrid materials based on POSS nanoparticles as inorganic part overcome some of the most important limitations intrinsic to sol-gel hybrid composites while maintaining the physical, chemical, and mechanical combined advantages of organic-inorganic systems. ${ }^{[7]}$

We demonstrated, for the first time to the best of our knowledge, the behaviour of POSS doped systems as disordered nanomaterials, a possibility never considered before. ${ }^{[8]}$ The dispersion of POSS nanoparticles at a molecular level defines highly homogeneous materials that, when doped with lasing dyes, allow coherent laser emission but, in addition and in spite of their nanometer size, the POSS particles sustain a weak optical scattering that helps lasing by elongating the light path inside the gain media, thus providing an extra feedback, a phenomenon central to the process called "incoherent random laser" or "lasing with intensity feedback". ${ }^{[9]}$ In this way, the laser action in systems based on dye-doped POSS materials is significantly enhanced, both in liquid- and solidphase. $^{[7]}$

The unique chemical and optical properties exhibited by POSS nanoparticles lead us to design new hybrid photonic systems based on POSS labelled with fluorescent dyes as pendant groups of their rigid inorganic core. Herein, we report the synthesis and characterization of new hybrid organic-inorganic dyes based on an azide-functionalized POSS as inorganic part and a 4,4-difluoro-4bora-3a,4a-diaza-s-indacene (BDP) chromophore as the organic component, selected for its interesting photophysical and photochemical properties both in liquid phase and in doped solid matrices. ${ }^{[10]}$ The new hybrid systems should exhibit highly efficient, stable, and tunable laser emission with improved thermal properties by the chemical attachment of the fluorophore to the rigid inorganic framework, strengthening their biomedical and photonic applications. In order to study the effect that both the linkage group of BDP to the POSS unit and the degree of functionalization of the inorganic core have on the optical properties, we proceeded to the synthesis of model dyes as well as mono- and octa-substituted BDPPOSS hybrid derivatives.

\section{Results and Discussion}

Synthesis and characterization: We have recently described the synthesis of octakis(3-azidopropyl)octasilsesquioxane (2), a highly symmetrical and topologically ideal cube-octameric POSS monomer containing eight azide groups (Scheme 1). ${ }^{[1]}$ Compound 2 could be readily obtained in one-step from commercially available octakis(3aminopropyl)octasilsesquioxane (1) using a highly efficient diazotransfer reaction promoted by nonaflyl azide, ${ }^{[12]}$ a shelf-stable diazotransfer reagent. The very mild conditions of this reaction prevented nucleophile-induced cage rearrangements ${ }^{[13]}$ that are common in alternative routes to $\mathbf{2}$ using nucleophilic substitution reactions with azide ion. ${ }^{[14]}$ Compound $\mathbf{2}$ is an excellent nanobuilding block for the synthesis of new functional nanocages with perfect 3-D cubic symmetry through copper(I)-catalyzed 1,3-dipolar azide-alkyne cycloaddition (CuAAC) with a variety of terminal alkynes. ${ }^{[11,14 a, c, d]}$ The versatility of this approach have been demonstrated in the preparation of the dye-POSS cluster 4 using the alkyne-substituted BDP fluorescent dye 3 (Scheme 2). ${ }^{[1]}$

We have now studied the monofunctionalization of octa-azide 2 with the alkyne-substituted BDP dye $\mathbf{3}$ (Scheme 3), which we used previously for the preparation of dye-POSS cluster 4 . This reaction would afford a POSS derivative $\mathbf{5}$ labeled with a single fluorescent probe and containing seven additional reactive azide groups ready for further functionalization with any molecule of interest having a terminal alkynyl group. Besides, compound $\mathbf{5}$ would be an interesting hybrid dye for the preparation of solid-state laser materials with improved thermal and chemical stability. The full details of our study of the CuAAC monofunctionalization reaction of octa-azide 2 under different reaction conditions will be published elsewhere. The optimized conditions involved the use of a 10 -fold molar excess of $\mathbf{2}$ over alkyne $\mathbf{3}$, to guarantee a high statistical selectivity for the monofunctionalized product $\mathbf{5}$, and the recently described $^{[15]}\left[\mathrm{Cu}\left(\mathrm{C} 18_{6}\right.\right.$ tren $\left.)\right] \mathrm{Br}$ catalyst with added Hünig's base in toluene as solvent under microwave heating. These optimized conditions afforded a high yield of $\mathbf{5}(82 \%)$, close to the expected statistical value (95.6\%). The rest of alkyne 3 was transformed into a complex mixture of polytriazolyl POSS products, as shown by ${ }^{1} \mathrm{H}$ NMR analysis of the remaining mixed fractions from column chromatography. The structure of $\mathbf{5}$ was unambiguously confirmed from its high-resolution mass spectrometry and multinuclear $\left({ }^{1} \mathrm{H}\right.$, ${ }^{13} \mathrm{C},{ }^{29} \mathrm{Si}$ ) NMR spectroscopy data (see Supporting Information).

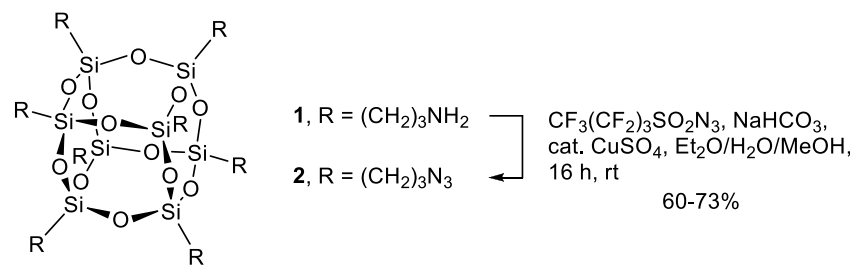

Scheme 1. One-step diazo-transfer synthesis of octaazido-POSS 2 from commercially available octaamino-POSS 1.

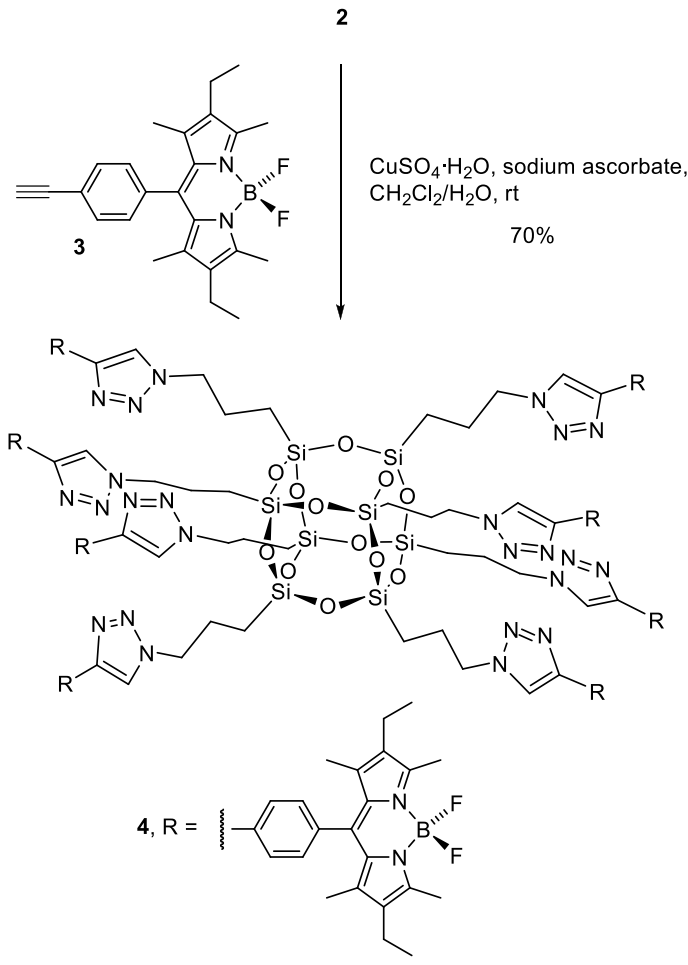

Scheme 2. "Click" synthesis of octa-BDP-POSS 4.

For the study of the photophysical properties of the BDP-POSS constructs $\mathbf{4}$ and $\mathbf{5}$, we also prepared the new BDP dye $\mathbf{6}$, as a model 
system where a methyl group has replaced the POSS core. Compound $\mathbf{6}$ was readily obtained by the CuAAC reaction of $\mathbf{3}$ with 1-azidobutane (Scheme 4).

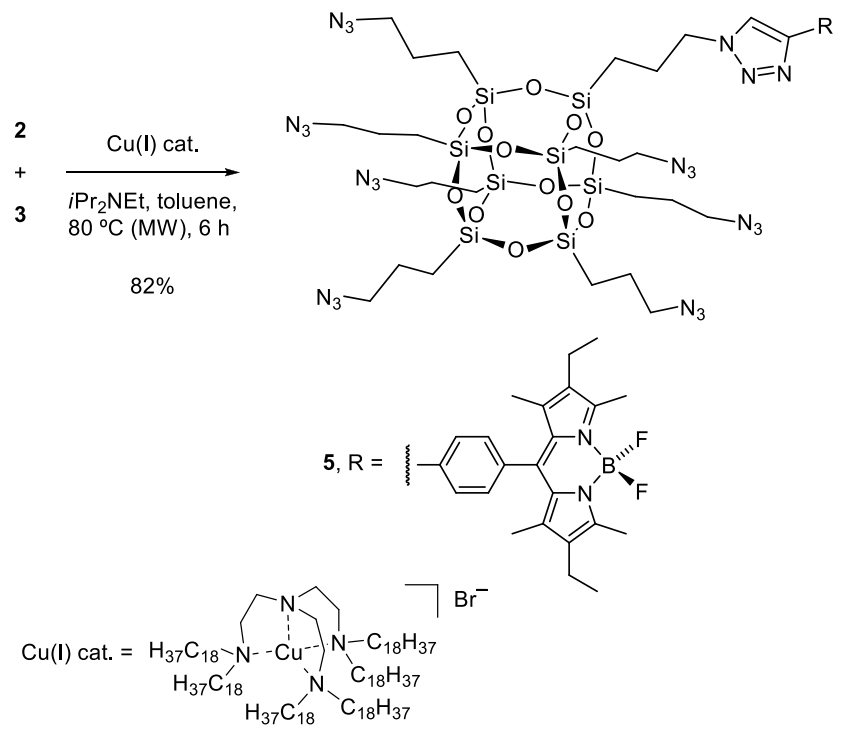

Scheme 3. Monofunctionalization of octaazido-POSS 2 with alkyne-functionalized BDP dye 3 .

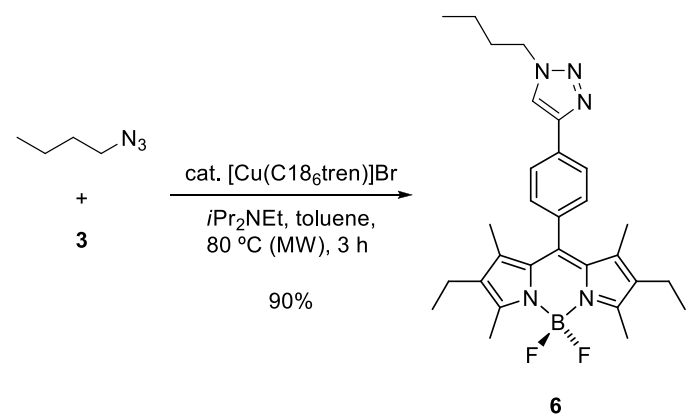

Scheme 4. Synthesis of model BDP dye 6.

\section{Photophysical and lasing characterization}

Studies were carried out in order to analyze the dependence of both the photophysical properties and laser performance of the new BDP dyes on different experimental parameters, such as the linkage group of the chromophore to the POSS core, the degree of functionalization of the core, the nature of the solvent and the composition of the host matrix.

Influence of substitution at C-8 of PM567 (Compounds 3 and 6): Before attaching the BDP derivatives to a POSS core, it is essential to characterize the influence of the linking unit on the photophysics of the BDP chromophore. To this aim, the corresponding model dyes will be firstly analyzed.

Photophysical characterization: The absorption spectra and fluorescence decay curves of model dyes $\mathbf{3}$ and $\mathbf{6}$ measured in the same solvent are depicted in Figure 1. In general, the shape and position of the spectral bands of both model dyes bearing the para phenyl substituted groups are similar to those of the parent PM567 dye (Figure 2) ) $^{[16]}$ and other 8-phenyl analogs. ${ }^{[17]}$ The steric hindrance introduced by the methyl groups flanking the meso position of the chromophore hampered the resonant interaction between the electronic clouds of the phenyl group and the BDP core. In fact, such a constrained structure resulted in a nearly perpendicular disposition of the phenyl group with respect to the chromophoric plane, reducing its influence on the BDP core. ${ }^{[18]}$

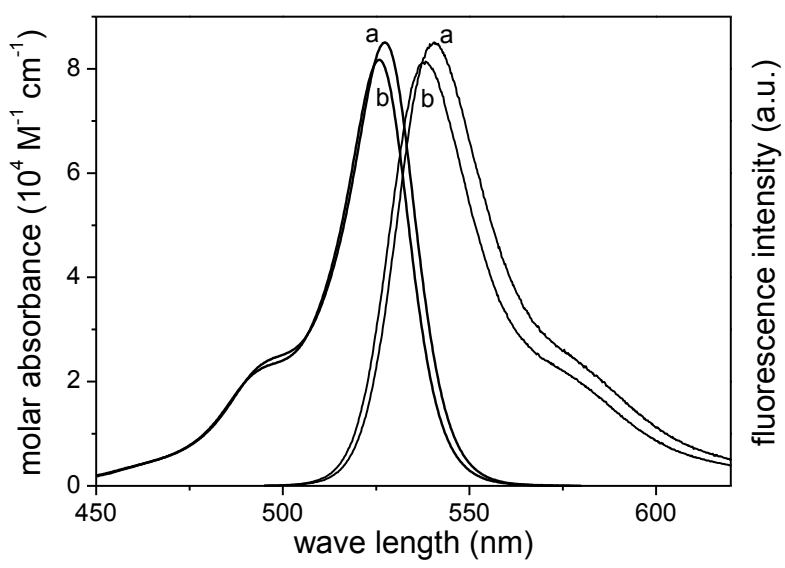

Figure 1. Absorption and fluorescence spectra of compound $\mathbf{3}$ (a) and $\mathbf{6}$ (b) in cyclohexane.
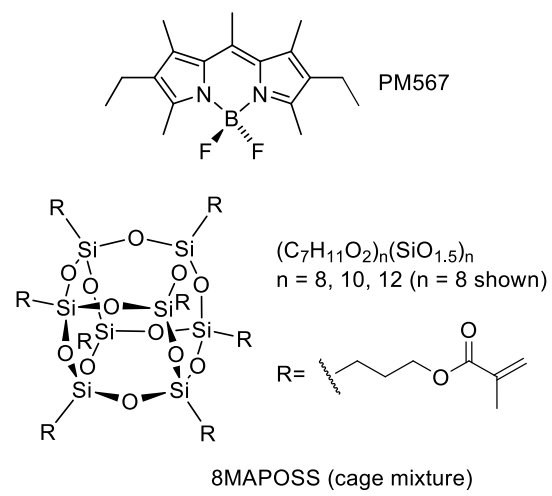

Figure 2.

Table 1 lists the photophysical properties of dyes 3-6 in a common solvent. For comparison purpose, the corresponding data of the parent BDP (PM567) dye, recorded under identical experimental conditions, are also included in Table 1 (see also Table S1 of Supporting Information for photophysical data in different solvents). With respect to the PM567 dye, the presence of a $p$-phenyl group linked to the meso position of the BDP core induced a slight bathochromic shift of the absorption and fluorescence bands, an increase of the non-radiative deactivation constant, and, consequently, a slight decrease of the fluorescence quantum yield and lifetime. It has been previously reported that the free rotation of such bulky groups enhances the internal conversion processes, and hence drastically reduces the fluorescence ability of the dye. ${ }^{[19]}$ However, in these model dyes the steric interaction with the flanking methyl groups should hinder, at least to some extent, the rotation of the phenyl ring. ${ }^{[18]}$ In spite of this geometrical restriction, it seems that the phenyl group might have some rotational freedom, increasing the vibrational coupling with the BDP core, which could 
explain the slight decrease of the fluorescence ability of the model dyes. ${ }^{[17]}$

Table 1. Photophysical properties of compounds 3,4, 5, 6, and PM567 (reference dye) ${ }^{[16]}$ in cyclohexane. ${ }^{[a]}$

\begin{tabular}{|c|c|c|c|c|c|c|c|}
\hline Compounds & $\lambda_{\mathrm{abs}}$ & $\varepsilon_{\max }$ & $\lambda_{\mathrm{fl}}$ & $\phi$ & $\tau$ & $\mathrm{k}_{\mathrm{fl}}$ & $\mathrm{k}_{\mathrm{nr}}$ \\
\hline 3 & 527.5 & 8.5 & 542.0 & 0.54 & 2.96 & 1.82 & 1.55 \\
\hline \multirow[t]{3}{*}{$4^{[\mathrm{b}]}$} & 523.0 & 38.0 & 545.0 & 0.14 & $3.41(37 \%)$ & - & - \\
\hline & & & & & $1.16(26 \%)$ & & \\
\hline & & & & & $0.12(37 \%)$ & & \\
\hline 5 & 526.0 & 5.8 & 540.0 & 0.60 & 3.86 & 1.55 & 1.03 \\
\hline 6 & 526.0 & 8.1 & 540.0 & 0.67 & 3.74 & 1.79 & 0.88 \\
\hline PM567 & 522.5 & 9.3 & 537.0 & 0.70 & 5.60 & 1.25 & 0.53 \\
\hline
\end{tabular}

[a] Absorption $\left(\lambda_{\text {abs }}, \pm 0.5 \mathrm{~nm}\right)$ and fluorescence $\left(\lambda_{\text {flu }}, \pm 0.5 \mathrm{~nm}\right)$ wavelength, molar absorption $\left(\varepsilon_{\max }, 10^{4} \mathrm{M}^{-1} \mathrm{~cm}^{-1}\right)$, fluorescence quantum yield $(\phi, \pm 0.05)$ and lifetime $(\tau$, $\pm 0.05 \mathrm{~ns})$, radiative $\left(\mathrm{k}_{\mathrm{fl}}, 10^{8} \mathrm{~s}^{-1}\right)$ and non-radiative $\left(\mathrm{k}_{\mathrm{nr}}, 10^{8} \mathrm{~s}^{-1}\right)$ deactivation rate constants. [b] Compound 4 was not soluble in cyclohexane, hence the data showed were obtained in acetone. The full data in different solvents are listed in Table S1 and S2 of the Supporting Information.

Table 2. Laser properties ${ }^{[a]}$ of the new 8-functionalized BDP dyes in liquid phase.

\begin{tabular}{lcccccc}
\hline & Compound 3 & \multicolumn{2}{l}{ Compound $\mathbf{5}$} & \multicolumn{2}{l}{ Compound $\mathbf{6}$} \\
Solvent & Eff $(\%)$ & $\lambda_{\text {la }}(\mathrm{nm})$ & Eff $(\%)$ & $\lambda_{\text {la }}(\mathrm{nm})$ & Eff $(\%)$ & $\lambda_{\text {la }}(\mathrm{nm})$ \\
\hline $\mathrm{CF}_{3} \mathrm{CH}_{2} \mathrm{OH}$ & 57 & 558 & 47 & 558 & 58 & 558 \\
$\mathrm{MeOH}$ & 50 & 563 & 52 & 560 & 50 & 558 \\
EtOH & 52 & 562 & 51 & 562 & 56 & 560 \\
EtOAc & 61 & 558 & 61 & 560 & 60 & 558 \\
Acetone & 50 & 559 & 50 & 561 & 52 & 557 \\
Cyclohexane & 35 & 562 & 25 & 561 & 21 & 555 \\
\hline
\end{tabular}

[a] Eff: energy conversion efficiency, $\lambda_{\mathrm{la}}$ : peak wavelength of the laser emission.

Laser properties: The lasing behavior of model dyes $\mathbf{3}$ and $\mathbf{6}$ was analyzed using the following protocol. First, we carried out a systematic analysis of the laser action of the new dyes in liquid phase to guide the selection of the best dye/host matrix combination among the quasi-unlimited compositions and structures of solid materials, to optimize their behavior attending to both lasing efficiency and photostability.

The dependence of the laser action on the concentration of the new BDP dyes was analyzed in ethyl acetate by varying the dye concentration whereas the other experimental parameters were kept constant. Under these experimental conditions, broad-line-width laser emission peaked at ca. $558 \mathrm{~nm}$ with pump threshold energy of $\sim 0.8 \mathrm{~mJ}$, beam divergence of $\sim 5 \mathrm{mrad}$ and pulse duration of $\sim 8 \mathrm{~ns}$ FWHM (full width at half maximum) was obtained from the new dyes when placed in a simple plane-plane non-tunable resonator.

Concentrations of $5 \times 10^{-4} \mathrm{M}$ and $6 \times 10^{-4} \mathrm{M}$ resulted in the highest lasing efficiencies (defined as the ratio between the energy of the dye laser output and the energy of the pump laser incident on the sample surface) for compound $3(61 \%)$ and $6(60 \%)$, respectively. The actual effect of the solvent on the dye laser action was analyzed in solutions with concentrations set at the values that optimize the lasing action and using the same solvents selected to analyze the photophysical properties of the new dyes. In all the selected solvents, the model dyes lased with high efficiency (Table 2), improving those exhibited by the parent dye PM567 (35\%) and by other 8 -substituted BDP dyes when pumped under identical experimental conditions. ${ }^{[20]}$

The new dyes turned out to be highly photostable since, after 100000 pump pulses at $10 \mathrm{~Hz}$, compounds 3 and $\mathbf{6}$ maintained $90 \%$ and $80 \%$ of their initial laser output, respectively, clearly improving the useful lifetime of the commercial PM567 as well as of other 8substituted BDP dyes when pumped under otherwise identical experimental conditions (Table 2 and Figure 3). ${ }^{[20]}$ This enhancement could be related to a higher photochemical stabilization of the chromophores rather than to a decline in the nonradiative deactivation processes since the new dyes present similar values for $\mathrm{k}_{\mathrm{nr}}$ than parent PM567. In addition, the lasing behaviour of the new dyes showed good correlation with their photophysical properties in dilute solutions. Thus, the similarity between the photophysical properties defined also similar laser behaviour for both dyes. Looking at the dependence of the laser action of each new dye on the solvent nature, it can be appreciated that the higher the fluorescence quantum yield was, the higher the lasing efficiency became.

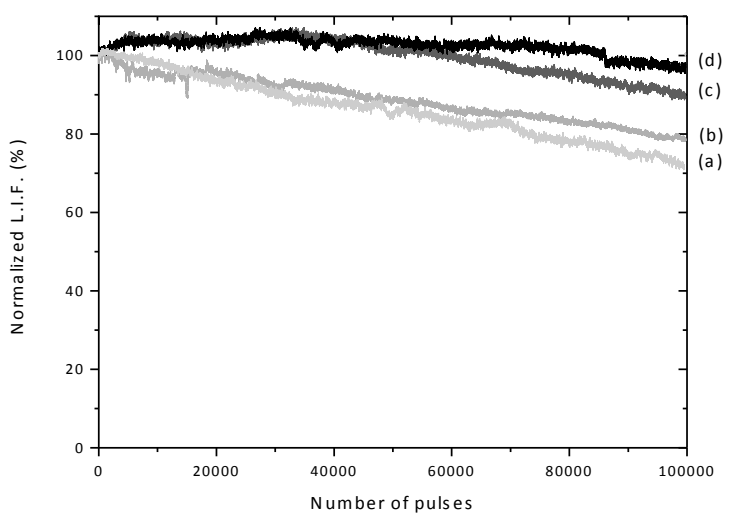

Figure 3. Normalized laser-induced fluorescence emission as a function of the number of pump pulses for PM567 (a), 6 (b), 3 (c), 5 (d) dye solutions in ethyl acetate. The residual laser-induced fluorescence emission after 100000 pulses for (a) to (d) were $71.4 \%, 78.8 \%, 89.5 \%$, and $97.3 \%$, respectively. Pump energy and repetition rate: 5.5 $\mathrm{mJ} /$ pulse and $10 \mathrm{~Hz}$, respectively.

The laser action of the new BDP dyes $\mathbf{3}$ and $\mathbf{6}$ in solid-state was analyzed in samples synthesized with the dye concentration that induced the highest lasing efficiency in liquid solution $\left(5 \times 10^{-4}\right.$ to $6 \times 10^{-4} \mathrm{M}$, depending on the dye). Methyl methacrylate (MMA) was chosen as the main monomeric component of the formulations 
because this ester mimics ethyl acetate, a solvent where both model dyes give rise to high lasing efficiencies.

First, compounds 3 and $\mathbf{6}$ were incorporated as true solutions into the solid homopolymer poly(methyl methacrylate) (PMMA), in order to establish the effect that the 8-substituent has on their lasing action when pumped under the experimental conditions described above. The results obtained are summarized in Table 3 . No significant differences were observed in the wavelength of the maximum laser emission of each dye between their liquid and solid solutions. Lasing efficiencies of 40 and $38 \%$, respectively, were measured, which are lower than those obtained from the corresponding ethyl acetate solutions, whereas the lasing photostability maintained similar values to those registered in liquid phase. In this regard, it has to be taken into account that the finishing of the surface of the solid samples relevant to the laser operation was not laser-grade, which is more detrimental for laser efficiency than for laser photostability. To put the present results in proper perspective, the lasing parameters of PM567 in PMMA were also measured under the same conditions. The results obtained (laser efficiency of $28 \%$ with the emission dropping to zero after 100000 pump pulses), ${ }^{[21]}$ were clearly worse than those registered with the new 8-functionalized BDP dyes.

Table 3. Laser properties of the new photosensitized materials.

\begin{tabular}{|c|c|c|c|c|c|c|c|c|c|}
\hline \multirow[b]{2}{*}{ Material $^{[\mathrm{a}]}$} & \multicolumn{3}{|c|}{ Compound 3} & \multicolumn{3}{|c|}{ Compound $\mathbf{5}$} & \multicolumn{3}{|c|}{ Compound 6} \\
\hline & $\begin{array}{l}\text { Eff } \\
(\%)\end{array}$ & $\begin{array}{l}\lambda_{\mathrm{la}} \\
(\mathrm{nm})\end{array}$ & $\begin{array}{l}\text { I } \\
(\%)\end{array}$ & $\begin{array}{l}\text { Eff } \\
(\%)\end{array}$ & $\begin{array}{l}\lambda_{\mathrm{la}} \\
(\mathrm{nm})\end{array}$ & $\begin{array}{l}\text { I } \\
(\%)\end{array}$ & $\begin{array}{l}\text { Eff } \\
(\%)\end{array}$ & $\begin{array}{l}\lambda_{\mathrm{la}} \\
(\mathrm{nm})\end{array}$ & $\begin{array}{l}\text { I } \\
(\%)\end{array}$ \\
\hline A & 40 & 560 & 97 & 52 & 560 & 100 & 38 & 559 & 77 \\
\hline B & 36 & 560 & 82 & & & & 31 & 558 & 72 \\
\hline $\mathrm{C}$ & & & & 56 & 558 & 100 & & & \\
\hline
\end{tabular}

[a] A: PMMA; B: Co(MMA/TFMA 70/30); C: Co(MMA/8MAPOSS 87/13).

The photophysical and lasing properties of the new model BDP dyes in solution indicated that a very polar protic solvent such as 2,2,2-trifluoroethanol is also a good liquid media for laser operation. To mimic this solvent, we have selected the monomer 2,2,2trifluoroethyl methacrylate (TFMA) for the preparation of linear copolymers with different proportions of MMA. The incorporation of the new dyes $\mathbf{3}$ and $\mathbf{6}$ into this fluorinated-based organic matrix did not improve their laser performance as compared to that obtained in pure PMMA homopolymer (Table 3). In fact, the presence of the fluorinated monomer in the matrix slightly decreased both the lasing efficiency and the photostability of the dyes. Although photobleaching of dyes can occur through several different mechanisms and, from a general point of view, can be considered to be quite complex, at low irradiances and under ambient atmosphere the primary photodegradation event of chromophores is believed to be photo-oxidation. As a result, factors that accelerate oxygen diffusion, such as the higher oxygen permeability of fluorinated materials, are expected to reduce the photostability of the new model BDP dyes.

In summary, the two new analogues of dye PM567, compounds 3 and 6, have demonstrated similar photophysical properties and higher lasing efficiency and photostability than the parent dye
PM567, both in liquid phase and when incorporated in solid matrices. Therefore, the chosen models are adequate candidates to be linked to the POSS unit, since the unique photophysical properties of a BDP chromophore such as PM567 are preserved after the introduction of the alkynyl or 1,2,3-triazolyl substituents at the para position of the phenyl ring. Furthermore, the attachment of the BDP to the POSS core is known to be an efficient means of photostabilizing BDP laser dyes.

Influence of the BDP-POSS click assembly: mono-substitution (Compound 5). Photophysical characterization: The linkage of the BDP to the POSS core (compound 5) had a minor effect on the spectral band positions and on the fluorescence lifetime, which remained close to those of the model BDP bearing the linking unit (compound 6, Table 1). However, the absorption transition probability is more affected by the presence of POSS (molar absorption decreases around 25\%) than the fluorescence transition, since the fluorescence quantum yield decreased only around $10 \%$ (Table 1). This behavior is related to a reduction/enhancement of the radiative/non-radiative deactivation processes, respectively, explaining the maintenance of the fluorescence lifetime (Table 1). The reduction of the $\mathrm{k}_{\mathrm{fl}}$ values is correlated with the decrease of the absorption probability, while the enhancement of the $k_{n r}$ values should be related to the large pendant POSS framework. A molecular structure with high conformational freedom increases the flexibility of the dye favoring internal conversion processes. ${ }^{[19]}$ In any case, the resulting hybrid dye retained a high fluorescence capacity (up to 0.65 with lifetimes around 4-6 ns; see Table S1 of the Supporting Information).

Laser properties: The laser action of the new hybrid dye was evaluated following the protocol described above. Under the selected experimental conditions, a $7.5 \times 10^{-4} \mathrm{M}$ concentration of the new hybrid BDP dye assured an optical density at the pumping wavelength $(532 \mathrm{~nm})$ similar to that selected for the characterization of the 8-functionaled BDP dyes $\mathbf{3}$ and $\mathbf{6}$. The hybrid dye $\mathbf{5}$ lased at ca. $560 \mathrm{~nm}$ with an efficiency ranging from $60 \%$ (ethyl acetate) to $25 \%$ (cyclohexane), and a high photostability with no sign of degradation in its laser output after 100000 pump pulses at $10 \mathrm{~Hz}$ repetition rate (Table 2 and Figure 3). It should be remarked that albeit the lasing performance of dyes $\mathbf{5}$ and $\mathbf{3}$ were similar, the absorption and fluorescence probability was lower for the hybrid dye. This fact can be related to our initial hypothesis: the POSS particles, with sizes below 5 nanometers, act as weak scattering centers in the Rayleigh limit (particle size much smaller than the emission wavelength), increasing the effective optical path inside the gain medium in a process known as non-resonant feedback (NRF) lasing, which add up incoherently to the conventional laser action in a way that increases the efficiency of the laser system. ${ }^{[8,22]}$ Under laser irradiation, the opening up of this new non-resonant feedback pathway explains the high laser performance of the new BDP-POSS cluster as well as the lack of correlation with its photophysical properties which are recorded under much lower excitation intensities.

Incorporation of the new BDP-POSS dye in PMMA improved remarkably the laser action as compared to that registered with dye 3 in the same matrix (material A, Table 3). Thus, for the hybrid dye, a laser efficiency as high as $52 \%$ was registered, without sign of degradation after 100000 pump laser pulses in the same position of the sample at $10 \mathrm{~Hz}$ repetition rate. Incorporation of methacrylPOSS (8MAPOSS cage mixture, Figure 2) nanoparticles in the 
media resulted in a further enhancement of the lasing performance. In this way, new solid materials based on copolymers of MMA with a $13 \%$ weight ratio of 8 MAPOSS doped with hybrid dye 5 reached a lasing efficiency of up to $56 \%$, while maintaining a high photostability (material C, Table 3 ).

To better assess the laser photostability of the new hybrid BDPPOSS dye 5, we proceeded to a longer run of pumping under more drastic conditions by irradiating the same position of the sample at $30 \mathrm{~Hz}$ repetition rate (Figure 4). The new hybrid dye solved in pure PMMA exhibited a high photostability, without any sign of degradation of its laser output after 400000 pump pulses. Thus, regarding laser efficiency and photostability, the new hybrid BDPPOSS cluster improved our previous results based on the parent PM567 dye doped hybrid matrices even when these matrices were based on copolymers of MMA with different weight ratios of 8MAPOSS. ${ }^{[21,23]}$

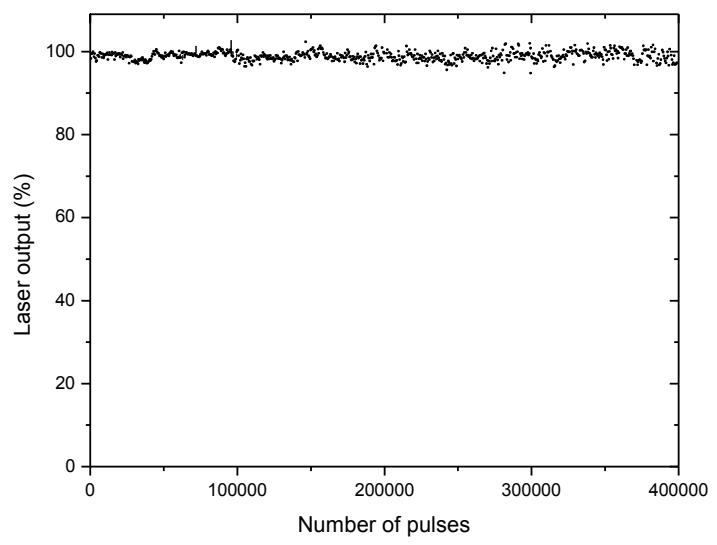

Figure 4. Normalized laser output as a function of the number of pump pulses in the same position of the sample for the new hybrid dye 5 incorporated into PMMA. Pump energy and repetition rate: $5.5 \mathrm{~mJ} /$ pulse and $30 \mathrm{~Hz}$, respectively.

Influence of the BDP-POSS click assembly: octa-substitution (Compound 4). Photophysical characterization: This multichromophoric hybrid dye was not soluble in apolar solvents even in diluted $\left(10^{-6} \mathrm{M}\right)$ solutions, but dissolved well in polar media such as acetone, ethyl acetate and 2,2,2-trifluoroethanol. Figure 5 shows the corresponding absorption and fluorescence spectra, together with the fluorescence decay curves. The presence of eight BDP units in the same molecule leaded to a large increase of the absorption transition probability, being $\varepsilon_{\max }$ up to $38 \times 10^{4} \mathrm{M}^{-1} \mathrm{~cm}^{-1}$ in acetone (Table 1), probably the largest reported for a BDP based system, that nevertheless was lower than that expected considering the absorption probability of model dye $6\left(8.1 \times 10^{4} \mathrm{M}^{-1} \mathrm{~cm}^{-1}\right.$, Table 1). Indeed, in the previously analyzed monosubstituted POSS (compound 5) it was also apparent that the linkage of the BDP unit to POSS core leaded to a reduction of the absorption transition probability (Table 1). Even more, the comparison of the normalized absorption spectra of the octasubstituted POSS 4 and the parent PM567 dye indicated that the spectrum of the hybrid material was wider, increasing the absorbance at the hipsochromic shoulder region (Figure 5). Such behaviour could be related to dye aggregation, particularly $\mathrm{H}$ or "sandwich" type dimers, where the transition moments of the chromophores are parallely disposed. ${ }^{[24]}$ Although BDP dyes usually have a low tendency to self- associate,${ }^{[19 c]}$ some authors have claimed the presence of aggregates in confined environments or in multichromophoric dyes where BDP cores are closely disposed through molecular bridges. ${ }^{[25]}$
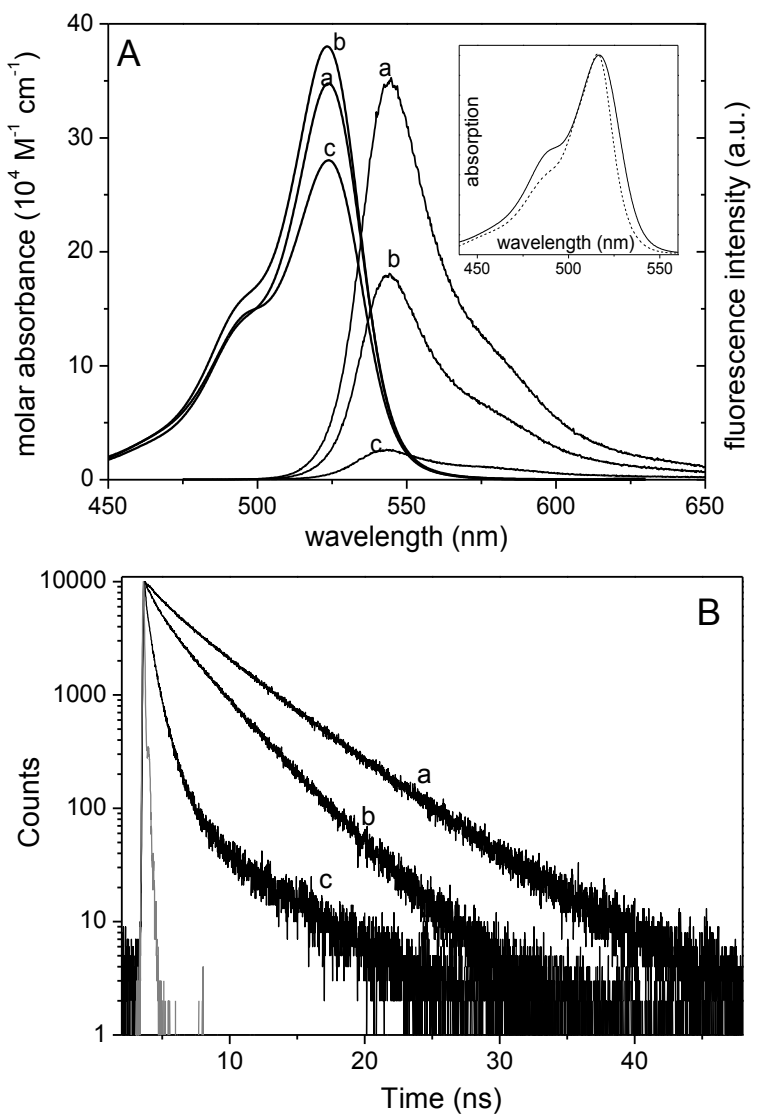

Figure 5. A) Absorption and fluorescence spectra of compound $\mathbf{4}$ scaled by its molar absorption and fluorescence quantum yield, respectively, in ethyl acetate (a), acetone (b) and trifluoroethanol (c). The normalized absorption spectra of PM567 (dashed) and compound 4 (solid) are also included. B) Fluorescence decay curves.

In order to get a deeper insight, we tried to simulate theoretically the most stable ground state conformation of compound $\mathbf{4}$ by means of the AM1 semiempirical method. Taking into account the high number of possible conformations of this molecule, we followed two different approaches for the geometry optimization. On one hand, a full optimization of the octasubstituted POSS was performed starting from a geometry with the BDP chromophores located as far as possible from each other and with the phenyl substituents oriented coplanar to the BDP system. On the other hand, we carried out a sequence of stepwise building of the molecule followed by full geometry optimization at each step starting from the bare octapropyl-POSS core, adding then the eight triazolyl rings and finally four of the eight phenyl-BDP substituents on one of the faces of the POSS cube, to obtain ultimately a simplified model of $\mathbf{4}$ in an energy-minimized conformation. It should be kept in mind the difficulty in handling such large and flexible structures, with many allowed conformations. In all cases, the final optimized geometry (Figure 6) revealed that the phenyl rings and their attached indacene subunits were not coplanar, as expected. Besides, the BDP chromophores did not occupy the available free volume, but rather tended to be in close contact, allowing through-space interactions between them. In fact, it can be observed that the BDP units tended to be paired with a cofacial arrangement of their transition moments parallel (Figure 6), allowing a $\pi-\pi$ stacking. In this H-type dimer, 
the BDP monomeric units were disposed forming a dihedral angle of $8^{\circ}$ and separated by $5 \AA$. However, due to the flexibility of the linking chains, the chromophores are not held tightly in a cofacial manner, which leads to a low exciton coupling and a low split of the absorption bands of the aggregate, ${ }^{[26]}$ explaining the slight changes observed in the absorption spectrum of the octasubstituted POSS compared to the free BDP dye (Figure 5). Indeed, a rough estimation of the aggregation degree, ${ }^{[27]}$ predicts a molar fraction of around 0.8 for the monomer and 0.10 for the dimer $(0.20$ for the monomeric units of the aggregate).

(a)

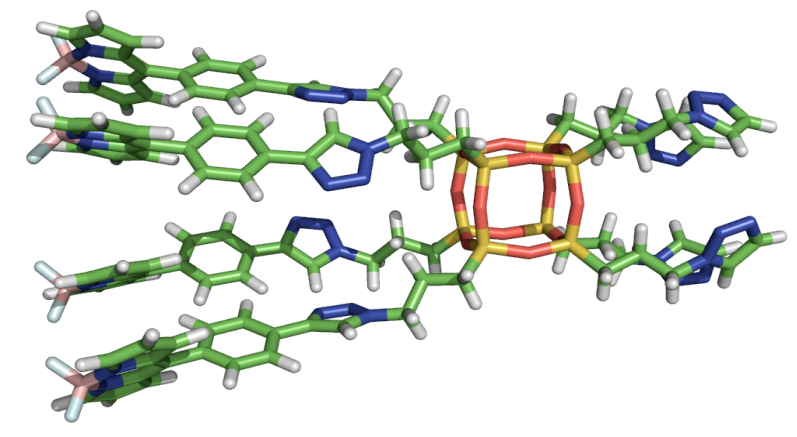

(b)

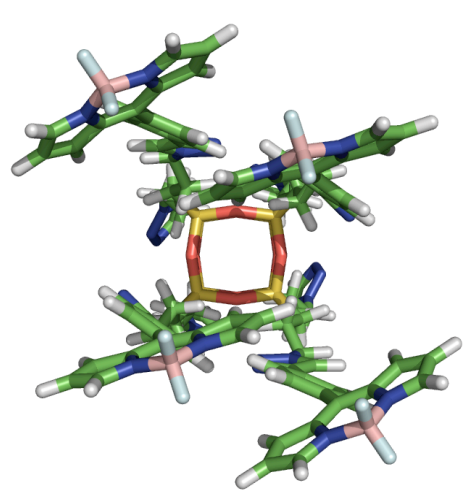

Figure 6. Optimized geometry (at AM1semiempirical level) of a simplified model of compound 4 lacking four of the eight phenyl-BDP substituents: (a) front view; (b) side view.

In spite of the multiple chromophores present in the molecule and their proximity, the recorded fluorescence band (Figure 5) resembled that of the model BDP dye (Figure 1), with no apparent new bands. However, the fluorescence quantum yield decreased $(\phi=$ 0.14 in acetone) with respect to the monosubstituted POSS $(\phi=$ $0.56)$, and even more in polar environments $(\phi=0.02$ in $2,2,2-$ trifluoroethanol; see Table S2 of the Supporting Information). Moreover, the fluorescence lifetime could not be further analyzed as a monoexponential, and a multiexponential fit was needed to properly adjust the decay curves (Figure 5). The deconvolution, regardless of the emission wavelength, consisted of a long and dominating lifetime ( $\tau=3.41 \mathrm{~ns}, 37 \%$ ), resembling that of BDP, and two shorter lifetimes (Table 1 and Table S2 of the Supporting Information: $\tau=1.16 \mathrm{~ns}, 26 \%$ and $\tau=0.12 \mathrm{~ns}, 37 \%$, in acetone). Such evolution was even more apparent in more polar media, where short lifetimes were largely favoured (Figure 5).
Apart from the static fluorescence quenching induced by the $\mathrm{H}$ type aggregate due to their inactive absorption in fluorescence, the multiexponential decay indicated a complex excited state dynamics. Indeed, the proximity of the BDP units, revealed in the optimized geometry of the octasubstituted POSS (Figure 6), could lead to extra quenching processes (i.e., electron transfer or interconversion between aggregates and monomers) giving rise to an overall loss of the fluorescence capacity. For example, dye aggregation quenches efficiently the emission from the monomer. ${ }^{[27]}$ Besides, the flexibility of the spacer connecting BDP units to the POSS core could give rise to a range of different relative arrangements of the BDP units, which should contribute to the loss of fluorescence. ${ }^{[19 c]}$ In this sense, the full optimization of compound $\mathbf{4}$ predicted a slight loss of planarity in the BDP chromophores, showing a "butterfly" like distortion along the transversal axis, while in the monosusbtituted POSS (compound 5) the indacene core remained fully planar. This lack of planarity, probably due to the high steric hindrance of such constrained structure in the octasubstituted POSS, should lead to an increase of the internal conversion probability. ${ }^{[28]}$ On the other hand, the tendency of the BDP chromophores to selfassociate should be higher in polar media, due to their hydrophobicity, thus explaining the drastic decrease of the fluorescence ability with increasing solvent polarity. Indeed, the hypsochromic absorption shoulder was clearer and also the calculated molar fraction of the aggregate was higher in polar solvents. In view of these results, octasubstituted POSS 4 should not be suitable as dye laser.

Laser properties: Hybrid dye 4 did not lase even under drastic pumping conditions. Indeed, all the above commented non-radiative pathways, mainly due to the presence of aggregates, greatly enhanced the losses in the resonator cavity, preventing the detection of the laser signal.

\section{Conclusion}

Octakis(3-azidopropyl)octasilsesquioxane (2) is a topologically ideal nanobuilding block for the efficient synthesis of mono- and octa-functionalized fluorescent nanocages through CuAAC reaction with alkyne-substituted BDP dyes. The controlled monofunctionalization of octa-azide $\mathbf{2}$ with BDP dye $\mathbf{3}$ resulted in a fluorescently labeled POSS derivative $\mathbf{5}$ containing seven additional reactive azide groups ready for further functionalization through CuAAC with any molecule of interest having a terminal alkynyl group. Full dye-substitution of POSS afforded a hybrid system characterized by low fluorescence ability, mainly in polar media. Quantum mechanical simulation provided a molecular base to get insight into the composition-structure-properties relationship of these hybrid systems. The optimized molecular geometry suggests that the BDP chromophores tend to be paired, leading to aggregation, which quenches effectively both fluorescence and laser emissions. However, the linkage of one BDP to the POSS core had a minor effect on the photophysics of the dye but improved significantly the laser properties of the final system with respect to those exhibited by the model dyes. In fact, the new hybrid dye exhibited lasing efficiency, up to $60 \%$ (in liquid phase) and $56 \%$ (in solid matrices), with high photostability, since the laser output remains at its initial value under very demanding pumping conditions $\left(4 \times 10^{5}\right.$ pump pulses in the same position of the sample at $30 \mathrm{~Hz}$ repetition rate). The new BDP-POSS cluster gives rise to a non-resonant feedback mechanism, which enhances its coherent laser performance. The versatility in the synthesis of the hybrid systems based on dye-linked 
POSS nanoparticles together with their improved optical properties and their nanofabrication capability, opens up the possibility of using these new photonic materials as alternative sources for optoelectronic devices, competing with dendronized or grafted polymers.

\section{Experimental Section}

General methods for synthesis and chemical characterisation. All melting points were measured with a Reicher Jung Thermovar micro-melting apparatus. Proton and carbon-13 nuclear magnetic resonance $\left({ }^{1} \mathrm{H}\right.$ NMR or ${ }^{13} \mathrm{C}$ NMR) spectra were recorded on a BRUKER AMX-300 (300 and $75 \mathrm{MHz}$, respectively), a Varian INOVA 300 (300 and $75 \mathrm{MHz}$, respectively), a Varian INOVA 400 (400 and $100 \mathrm{MHz}$, respectively) spectrometers. Silicon-29 nuclear magnetic resonance spectra were measured on a Varian INOVA 400 spectrometer $(79.5 \mathrm{MHz})$. Chemical shifts are expressed in parts per million ( $\delta$ scale) downfield from tetramethylsilane and are referenced to residua peaks of the deuterated NMR solvent used or to internal tetramethylsilane. Data are presented as follows: chemical shift, multiplicity $(\mathrm{s}=$ singlet, $\mathrm{d}=$ doublet, $\mathrm{t}=$ triplet, $\mathrm{m}$ $=$ multiplet and/or multiple resonances, $\mathrm{b}=$ broad), integration, coupling constants in hertz (Hz), and assignment. Proton and carbon-13 assignments are based on DQ-COSY, HSQC, and HMBC correlation experiments. Thin layer chromatography (TLC) was performed with Merck Silica Gel $60 \mathrm{~F}_{254}$ plates and Merck Aluminum oxide neutral 60 $\mathrm{F}_{254}$ plates. Chromatograms were visualized using UV light $254 / 365 \mathrm{~nm}$. For detection of azides, the chromatograms were first dipped in a $1 \%(\mathrm{w} / \mathrm{v})$ solution of $\mathrm{Ph}_{3} \mathrm{P}$ in EtOAc, dried at $\mathrm{rt}$, then dipped in a $1 \%$ or $5 \%(\mathrm{w} / \mathrm{v})$ solution of ninhydrin in $95 \%$ aqueous $\mathrm{EtOH}$ and finally charred on a hot plate. ${ }^{[29]}$ Column chromatography was performed with Merck neutral aluminium oxide or Merck silica gel, grade 60, 230-400 mesh. Mass spectra were recorded on a MALDI Voyager-DE PRO time-of-flight (TOF) spectrometer (Applied Biosystems), using a 2,5-dihydroxybenzoic acid matrix, or in an Agilent/HP $1100 \mathrm{LC} / \mathrm{MSD}$ spectrometer using ESI or APCI sources. Anhydrous solvents were prepared according to standard methods by distillation over drying agents or via elution through a Pure Solv ${ }^{\mathrm{TM}}$ column drying system ${ }^{[30]}$ from Innovative Technology, Inc. All other solvents were of HPLC grade and were used as provided. All reactions were carried out with magnetic stirring and, if air or moisture sensitive, in oven-dried glassware under argon. Microwave irradiation experiments were performed with a single-mode Discover System from CEM Corporation, using standard Pyrex tubes ( 10 or $35 \mathrm{~mL}$ capacity) sealed with a rubber cap.

Materials: Pyrromethene 567 (laser grade, Exciton) was used as received with a purity $>99 \%$ (checked by spectroscopic and chromatographic methods). Solvents for laser studies were of spectroscopic grade (Merck, Aldrich or Sigma) and were used without purification. Linear and crosslinked copolymers were obtained by copolymerization of methyl methacrylate (MMA) with different volumetric proportions of the monofunctional fluorinated monomer 2,2,2-trifluoroethyl methacrylate (TFMA) and of methacryl-POSS (8MAPOSS cage mixture, from Hybrid Plastics ${ }^{\mathrm{TM}}$ ). All monomers were purchased from Aldrich. MMA was purified before use while TFMA and 8MAPOSS were used as received. 2,2'-Azobis(isobutyronitrile) (AIBN) (Acros) was used as thermal initiator of polymerization. Azido-POSS 2 was prepared as described previously. Copper(I) catalyst $\left[\mathrm{Cu}\left(\mathrm{C} 18_{6}\right.\right.$ tren $\left.)\right] \mathrm{Br} \quad\left(\mathrm{C} 18_{6}\right.$ tren $=\operatorname{tris}(2$ dioctadecylaminoethyl)amine) was prepared following described procedures. ${ }^{[15 \mathrm{a}]}$

Octakis\{3-[4'-(4"-(2",,8,"-diethyl-5,",,5",-difluoro-1,",,3,",,7,",,9",-

tetramethyldipyrrolo[1",,2",-c:2",,1",f][1",,3",,2",']diazaborinin-4",-ium-5",uid-10','yl)phenyl)-1'H-1',2',3'-triazol-1'-yl|propyl\}octasilsesquioxane (4): Тo a solution of azido-POSS 2 (20 mg, $0.018 \mathrm{mmol}$ ) and 4,4-difluoro-8-(4'-ethynylphenyl)1,3,5,7-tetramethyl-2,6-diethyl-4-bora-3a,4a-diaza-s-indacene $\quad(3)^{[31]} \quad(72 \mathrm{mg}, \quad 0,178$ $\mathrm{mmol})$ in $\mathrm{CH}_{2} \mathrm{Cl}_{2}(0.9 \mathrm{~mL})$, was added a solution of $\mathrm{CuSO}_{4} \cdot 5 \mathrm{H}_{2} \mathrm{O}(2.5 \mathrm{mg}, 0.010$ $\mathrm{mmol})$ and sodium ascorbate $(9 \mathrm{mg}, 0.045 \mathrm{mmol})$ in water $(0.6 \mathrm{~mL})$. After stirring for $4.5 \mathrm{~h}$ at $\mathrm{rt}$, a saturated aqueous solution of EDTA $(1 \mathrm{~mL})$ was added, the mixture was vigorously stirred for $30 \mathrm{~min}$, the phases were separated, and the aqueous layer was extracted with $\mathrm{CH}_{2} \mathrm{Cl}_{2}(3 \times 3 \mathrm{~mL})$. The organic layers were combined, dried over $\mathrm{Na}_{2} \mathrm{SO}_{4}$, and the solvent was removed at reduced pressure. The crude was purified by flash column chromatography (hexane/EtOAc 1:5) to afford $4(54 \mathrm{mg}, 70 \%)$ as a red powder. M.p. (from $\mathrm{CH}_{2} \mathrm{Cl}_{2}$ ): $290{ }^{\circ} \mathrm{C}$ (decomposition). $R_{\mathrm{f}}=0.75$ (hexane/EtOAc 1:5). ${ }^{1} \mathrm{H}$ NMR $\left(400 \mathrm{MHz}, \mathrm{CDCl}_{3}\right) \delta=0.68-0.75\left(\mathrm{~m}, 16 \mathrm{H}, \mathrm{Si}_{-} \mathrm{CH}_{2} \mathrm{CH}_{2} \mathrm{CH}_{2}\right), 0.93(\mathrm{t}, 48 \mathrm{H}, J=$ $7.4 \mathrm{~Hz}, 16 \times\left(\mathrm{CH}_{3} \mathrm{CH}_{2}\right), 1.30\left(\mathrm{~s}, 48 \mathrm{H}, 16 \times \mathrm{CH}_{3}-\mathrm{C}\right), 2.13-2.18\left(\mathrm{~m}, 16 \mathrm{H}, \mathrm{SiCH}_{2} \mathrm{CH}_{2} \mathrm{CH}_{2}\right)$, 2.25 (q, $\left.32 \mathrm{H}, J=7.4,16 \times \mathrm{CH}_{2} \mathrm{CH}_{3}\right), 2.51\left(\mathrm{~s}, 48 \mathrm{H}, 16 \times \mathrm{CH}_{3}-\mathrm{C}\right), 4.46(\mathrm{t}, 16 \mathrm{H}, J=6.9 \mathrm{~Hz}$, $\left.\mathrm{SiCH}_{2} \mathrm{CH}_{2} \mathrm{CH}_{2}\right), 7.32\left(\mathrm{~d}, 16 \mathrm{H}, J_{\mathrm{AB}}=8.2 \mathrm{~Hz}, 2 \times \mathrm{CH} \mathrm{Ar}\right), 8.01\left(\mathrm{~d}, 16 \mathrm{H}, J_{\mathrm{AB}}=8.2,2 \times \mathrm{CH}\right.$ $\mathrm{Ar}), 8.15(\mathrm{~s}, 8 \mathrm{H}$, in $1,2,3$-triazole $) .{ }^{13} \mathrm{C} \mathrm{NMR}\left(100 \mathrm{MHz}, \mathrm{CDCl}_{3}\right) \delta=8.7$ $\left(\mathrm{SiCH}_{2} \mathrm{CH}_{2} \mathrm{CH}_{2}\right), 11.9\left(\mathrm{CH}_{3}\right), 12.5\left(\mathrm{CH}_{3}\right), 14.6\left(\mathrm{CH}_{3}-\mathrm{CH}_{2}\right), 17.0\left(\mathrm{CH}_{3}-\mathrm{CH}_{2}\right), 24.1$ $\left(\mathrm{SiCH}_{2} \mathrm{CH}_{2} \mathrm{CH}_{2}\right), 52.4\left(\mathrm{SiCH}_{2} \mathrm{CH}_{2} \mathrm{CH}_{2}\right), 120.7(\mathrm{CH}$ in $1,2,3$-triazole $), 126.1(\mathrm{CH}$ phenyl), 129.0 ( $\mathrm{CH}$ phenyl), 130.1, 131.2, 133.1, 135.8, 137.9, 139.2 (C in 1,2,3triazole), 147.1, 154.0. ${ }^{29} \mathrm{Si}$ NMR (79.5 MHz, $\left.\mathrm{CDCl}_{3}\right) \delta=-67.1$. UV/Vis (EtOAc): $\lambda_{\max }$ $=523 \mathrm{~nm} \varepsilon=432362 \mathrm{~mol}^{-1} \mathrm{dm}^{3} \mathrm{~cm}^{-1}$ MALDI-TOF (2,5-dihydroxybenzoic acid matrix) $m / z: 4304[\mathrm{M}-\mathrm{F}]^{+}$.
Mono-BDP-POSS 5: To a solution of azido-POSS $2(134 \mathrm{mg}, 0.123 \mathrm{mmol})$ and 4,4difluoro-8-(4'-ethynylphenyl)-1,3,5,7-tetramethyl-2,6-diethyl-4-bora-3a,4a-diaza-sindacene $(3)(5 \mathrm{mg}, 0.012 \mathrm{mmol})$ in toluene $(1 \mathrm{~mL})$, under argon, was added $\left[\mathrm{Cu}\left(\mathrm{C} 18_{6}\right.\right.$ tren $\left.)\right] \mathrm{Br}(2.2 \mathrm{mg}, 0.001 \mathrm{mmol})$ and $i \operatorname{Pr}_{2} \mathrm{NEt}(6.5 \mu \mathrm{L}, 0.037 \mathrm{mmol})$. The mixture was stirred for $6 \mathrm{~h}$ at $80{ }^{\circ} \mathrm{C}$ under microwave irradiation. The solvent was removed at reduced pressure and the residue was purified by flash column chromatography $\left(\mathrm{SiO}_{2}\right.$, hexane/EtOAc 12:1 to 5:3) to recover excess starting material 2 (113 $\mathrm{mg}, 94 \%$ recovery of excess $\mathbf{2}$ employed) and $\mathbf{5}$ as a red viscous oil $(15.1 \mathrm{mg}$, $82 \%) . \quad R_{\mathrm{f}}=0.61$ (hexane/ EtOAc 5:3). ${ }^{1} \mathrm{H}$ NMR $\left(400 \mathrm{MHz}, \mathrm{CDCl}_{3}\right) \delta=0.71-0.76(\mathrm{~m}$, $\left.14 \mathrm{H}, \mathrm{Si}-\mathrm{CH}_{2} \mathrm{CH}_{2} \mathrm{CH}_{2}\right), 0.83-0.98\left(\mathrm{~m}, 2 \mathrm{H}, \mathrm{Si}^{*} \mathrm{CH}_{2} \mathrm{CH}_{2} \mathrm{CH}_{2}\right), 0.97(\mathrm{t}, 6 \mathrm{H}, J=7.55 \mathrm{~Hz}$, $\left.\mathrm{CH}_{3}-\mathrm{CH}_{2}\right), 1.34\left(\mathrm{~s}, 6 \mathrm{H}, \mathrm{CH}_{3}-\mathrm{C} 1, \mathrm{CH}_{3}-\mathrm{C} 7\right), 1.66-1.74\left(\mathrm{~m}, 14 \mathrm{H}, \mathrm{SiCH}_{2} \mathrm{CH}_{2} \mathrm{CH}_{2}\right), 2.06-$ $2.13\left(\mathrm{~m}, 2 \mathrm{H}, \mathrm{Si}^{*} \mathrm{CH}_{2} \mathrm{CH}_{2} \mathrm{CH}_{2}\right), 2.30\left(\mathrm{q}, 4 \mathrm{H}, J=7.51 \mathrm{~Hz} \mathrm{CH}_{2} \mathrm{CH}_{3}\right), 2.54\left(\mathrm{~s}, 6 \mathrm{H}, \mathrm{CH}_{3}-\mathrm{C} 3\right.$, $\mathrm{CH}_{3}$-C5), $3.26\left(\mathrm{td}, 14 \mathrm{H}, J=6.83 ; 1.42 \mathrm{~Hz}, \mathrm{CH}_{2} \mathrm{~N}_{3}\right), 4.43\left(\mathrm{t}, 2 \mathrm{H}, J=7.11 \mathrm{~Hz}, \mathrm{CH}_{2}-\mathrm{N}=\mathrm{N}\right)$ $7.36\left(\mathrm{~d}, 2 \mathrm{H}, J_{\mathrm{AB}}=8.43 \mathrm{~Hz}, 2 \mathrm{xCH}\right.$ phenyl), $7.97\left(\mathrm{~d}, 2 \mathrm{H}, J_{\mathrm{AB}}=8.43 \mathrm{~Hz}, 2 \mathrm{xCH}\right.$ phenyl), $7.86\left(\mathrm{~s}, 1 \mathrm{H}\right.$, in 1,2,3-triazole) ppm. ${ }^{13} \mathrm{C}$ NMR $\delta=9.3\left(\mathrm{SiCH}_{2} \mathrm{CH}_{2} \mathrm{CH}_{2}\right), 12.6\left(\mathrm{CH}_{3}\right), 12.7$ $\left(\mathrm{CH}_{3}\right), 14.9\left(\mathrm{CH}_{3}-\mathrm{CH}_{2}\right), \quad 17.3\left(\mathrm{CH}_{3}-\mathrm{CH}_{2}\right), 22.7\left(\mathrm{SiCH}_{2} \mathrm{CH}_{2} \mathrm{CH}_{2}\right), 24.4\left(\mathrm{Si}^{*} \mathrm{CH}_{2} \mathrm{CH}_{2}\right.$ $\left.\mathrm{CH}_{2}\right), 52.8\left(\mathrm{CH}_{2}-\mathrm{N}=\mathrm{N}\right), 53.5\left(\mathrm{CH}_{2} \mathrm{~N}_{3}\right), 120.1(\mathrm{CH}$ de 1,2,3-triazole), $126.4(\mathrm{CH}$ phenyl), 129.2 (CH phenyl), 130.9, 131.3, 133.0, 135.9, 138.5, 139.8 (C in 1,2,3-triazole), 147.4, $154.1\left[\mathrm{Si}^{*}=\right.$ silicon atom with the $\left(1,2,3\right.$-triazol-1-yl)propyl substituent]. ${ }^{29} \mathrm{Si} \mathrm{NMR} \delta=$ $-66.92,-66.97,-67.53$ (3:4:1 relative intensities) ppm. UV/Vis (EtOAc): $\lambda_{\max } 523 \mathrm{~nm}(\varepsilon$

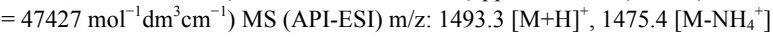

BDP dye 6: a) Synthesis of 1-butylazide. A solution of 1-bromobutane (1.0 g, 7.5 $\mathrm{mmol})$ and $\mathrm{NaN}_{3}(950 \mathrm{mg}, 14.6 \mathrm{mmol})$ in DMF $(15 \mathrm{~mL})$ was stirred for $15 \mathrm{~h}$ at $120^{\circ} \mathrm{C}$. The mixture was poured onto water and extracted 3 times with toluene (final concentration $0.04 \mathrm{M}$ assuming that the reaction is quantitative), dried $\left(\mathrm{Na}_{2} \mathrm{SO}_{4}\right)$ and used without further purification. b) CuAAC reaction: To a solution of 1-butylazide in toluene (2.23 mL 0.04M, $0.080 \mathrm{mmol}$ ) and 4,4-difluoro-8-(4'-ethynylphenyl)-1,3,5,7tetramethyl-2,6-diethyl-4-bora-3a,4a-diaza-s-indacene (3) $(25 \mathrm{mg}, 0.062 \mathrm{mmol})$, under argon, was added $\left[\mathrm{Cu}\left(\mathrm{C} 18_{6}\right.\right.$ tren $\left.)\right] \mathrm{Br}(11 \mathrm{mg}, 0.006 \mathrm{mmol})$ and $i \operatorname{Pr}_{2} \mathrm{NEt}(32 \mu \mathrm{L}, 0.185$ mmol). After stirring for $3 \mathrm{~h}$ at $80{ }^{\circ} \mathrm{C}$ under microwave irradiation, the solvent was removed at reduced pressure and the residue was purified by flash column chromatography (hexane/EtOAc 1:5) to afford 6 as a red crystalline powder $(28 \mathrm{mg}$, $90 \%$ ). $R_{\mathrm{f}}=0.44$ (hexane/EtOAc 5:3). M.p. (from EtOAc): $232-235^{\circ} \mathrm{C} .{ }^{1} \mathrm{H}$ NMR $(400$ $\left.\mathrm{MHz}, \mathrm{CDCl}_{3}\right) \delta=0.98\left(\mathrm{t}, 6 \mathrm{H}, J=7.5, \mathrm{CH}_{3}-\mathrm{CH}_{2}\right) ; 1.00\left(\mathrm{t}, 3 \mathrm{H}, J=7.3 \mathrm{CH}_{3}-\left(\mathrm{CH}_{2}\right)_{3}-\mathrm{N}\right)$; $1.34\left(\mathrm{~s}, 6 \mathrm{H}, \mathrm{CH}_{3}-\mathrm{C} 1, \mathrm{CH}_{3}-\mathrm{C} 7\right) ; 1.37-1.49\left(\mathrm{~m}, 2 \mathrm{H}, \mathrm{CH}_{2}-\left(\mathrm{CH}_{2}\right)_{2}-\mathrm{N}\right) ; 1.88-2.04(\mathrm{~m}$, $2 \mathrm{H}, \mathrm{CH}_{2}-\mathrm{CH}_{2}-\mathrm{N}$ ); 2.31 (q, $\left.4 \mathrm{H}, J=7.5, \mathrm{~Hz}, \mathrm{CH}_{2}-\mathrm{CH}_{3}\right) ; 2.54$ (s, 6H, $\mathrm{CH}_{3}-\mathrm{C} 3, \mathrm{CH}_{3}-\mathrm{C} 5$ ); $4.44\left(\mathrm{t}, 2 \mathrm{H}, J=7.2 \mathrm{~Hz} \mathrm{CH}_{2}-\mathrm{N}\right) ; 7.35\left(\mathrm{~d}, 2 \mathrm{H}, J_{\mathrm{AB}}=8.3 \mathrm{~Hz}, \mathrm{CH}\right.$ phenyl), $7.84(\mathrm{~s}, 1 \mathrm{H}$, in 1,2,3-triazole); 7.97 (d, $2 \mathrm{H}, \mathrm{J}_{\mathrm{AB}}=8.3 \mathrm{~Hz}, \mathrm{CH}$ phenyl) ppm. ${ }^{13} \mathrm{C}$ NMR $(100 \mathrm{MHz}$, $\left.\mathrm{CDCl}_{3}\right) \delta=12.1\left(\mathrm{CH}_{2}-\mathrm{CH}_{3}\right), 12.7\left(\mathrm{CH}_{3}-\mathrm{C} 1, \mathrm{CH}_{3}-\mathrm{C} 7\right), 13.7\left(\mathrm{CH}_{3}-\mathrm{C} 3, \mathrm{CH}_{3}-\mathrm{C} 5\right), 14.8$ $\left(\mathrm{CH}_{3}-\left(\mathrm{CH}_{2}\right)_{3}-\mathrm{N}\right), 17.2\left(\mathrm{CH}_{2}-\mathrm{CH}_{3}\right), 19.9\left(\mathrm{CH}_{2}-\left(\mathrm{CH}_{2}\right)_{2}-\mathrm{N}\right), 32.5\left(\mathrm{CH}_{2}-\mathrm{CH}_{2}-\mathrm{N}\right), 50.4$ $\left(\mathrm{CH}_{2}-\mathrm{N}\right), 119.9(\mathrm{CH}$ in 1,2,3-triazole), $126.4(\mathrm{CH}$ phenyl), $129.0(\mathrm{CH}$ phenyl), 130.9, $131.4,133.0,135.7,138.5,139.9,147.2,153.9 \mathrm{ppm}$. UV/Vis $(E t O A c): \lambda_{\max }(\varepsilon)=522 \mathrm{~nm}$ $\left(108900 \mathrm{~mol}^{-1} \mathrm{dm}^{3} \mathrm{~cm}^{-1}\right)$. MS (API-ESI) m/z: $504.3[\mathrm{M}]^{+}$.

Preparation of solid polymeric samples: The new BDP derivatives were incorporated into the different solid matrices following the procedure previously described. ${ }^{[32]}$ The solid monolith laser samples were cast in cylindrical shape, forming rods of $10 \mathrm{~mm}$ diameter and $10 \mathrm{~mm}$ length. A cut was made parallel to the axis of cylinder to obtain a lateral flat surface of $\approx 6 \times 10 \mathrm{~mm}$. This surface as well as the ends of the laser rods was prepared for lasing experiments by using a grinding and polishing machine (Phoenix Beta 4000, Büehler) until optical-grade finished. The planar grinding stage was carried out with a Texmet 1000 sand paper (Buehler) using a diamond polishing compound of 6 $\mu \mathrm{m}$ as an abrasive in mineral oil as a lubricant. The final polishing stage was realized with a G-Tuch Microcloth (Buehler), using a cloth disk Mastertex (Buehler) with diamond of $1 \mu \mathrm{m}$ in mineral oil as an abrasive type.

Methods. Photophysical properties: The photophysical properties were registered in diluted solutions (around $2 \times 10-6 \mathrm{M}$ ), prepared by adding the corresponding solvent to the residue from the adequate amount of a concentrated stock solution in acetone, after vacuum evaporation of this solvent. UV-Vis absorption and fluorescence spectra were recorded on a Cary 4E spectrophotometer and on a SPEX Fluorolog 3-22 spectrofluorimeter, respectively. Fluorescence quantum yields $(\phi)$ were evaluated from corrected spectra, using a diluted solution of PM567 (Exciton, laser grade) dye ( $\phi=$ 0.91 in methanol) as reference. ${ }^{[16]}$ Radiative decay curves were registered by the time correlated single-photon counting technique (Edinburgh Instruments, model FL920). Fluorescence emission was monitored at the maximum emission wavelength after excitation at $470 \mathrm{~nm}$ by means of a diode laser (PicoQuant, model LDH470) with 150 ps FWHM pulses. The fluorescence lifetime $(\tau)$ was obtained after the deconvolution of the instrumental response signal from the recorded decay curves by means of an iterative method. The goodness of the exponential fit was controlled by statistical parameters (chi-square, Durbin-Watson and the analysis of the residuals). The rate constant of radiative $(\mathrm{kfl})$ and non-radiative $(\mathrm{knr})$ deactivations were calculated by means of: $\mathrm{kfl}=\phi / \tau$ and $\mathrm{knr}=(1-\phi) / \tau$

The ground state geometry in the gas phase of the BDP-POSS hybrid dyes was fully optimized with the semiempirical AM1 method implemented in the Gaussian 09 software compiled in an informatic cluster. 
Lasing properties: Liquid solutions of dyes were contained in 1-cm optical-path quartz cells that were carefully sealed to avoid solvent evaporation during experiments. Both the liquid cells and the solid samples were transversely pumped at $532 \mathrm{~nm}$ with $5.5 \mathrm{~mJ}$, 6 ns FWHM pulses from a frequency-doubled Q-switched Nd:YAG laser (Monocrom OPL-10) at a repetition rate of up to $10 \mathrm{~Hz}$. Most representative samples were also pumped at $30 \mathrm{~Hz}$ with $3.5 \mathrm{~mJ}, 10 \mathrm{~ns}$ FWHM pulses from a diode pumped, frequency doubled, Q-switched Nd:YAG laser (Monocrom HALAZEN 532-12). Details of the experimental system can be found elsewhere. ${ }^{[33]}$

The photostability of each dye in liquid phase was also evaluated under experimental conditions identical to those selected to irradiate the fluorophores embedded in solid polymeric matrices, which will allow later comparison of their stability in liquid and solid phases under laser irradiation. Because the irradiated volume in solid samples was estimated to be $10 \mu \mathrm{L}$, capillary tubes into which ethyl acetate solutions of dyes were incorporated offer the best geometry to reproduce the volume irradiated in the solid samples, thus maintaining the same laser pump conditions in both cases. Although the low optical quality of the capillary prevents laser emission from the dyes, information about photostabilities can be obtained by monitoring the decrease in laser-induced fluorescence intensity, excited transversally to the capillary, as a function of the number of pump pulses at $10 \mathrm{~Hz}$ repetition rate. The fluorescence emission was monitored perpendicular to the exciting beam, and its collection and analysis was carried out with the same set-up selected to characterize the laser emission from dyes incorporated into solid samples.

\section{Acknowledgements}

We thank the Spanish Ministerio de Ciencia e Innovación (projects MAT2007-65778 C02-01, MAT2007-65778-C02-02, TRA2009-0144, CTQ-2006-15515-C02-02/BQU, and CTQ2009-14551-C02-02), Comunidad de Madrid (project S2009/PPQ-1634 "AVANCAT") and Gobierno Vasco (IT339-10) for financial support. We also thank Ministerio de Ciencia e Innovación for a FPU predoctoral fellowship to B. T. and C.S.I.C. for a JAE-PREDOC fellowship to M. E. P.-O. The SGI/IZO-SGIker UPV/EHU is gratefully thanked for allocation of computational resources.

[1] For reviews, see: a) D. B. Cordes, P. D. Lickiss, F. Rataboul, Chem. Rev. 2010, 110, 2081-2173; b) P. D. Lickiss, F. Rataboul, Adv. Organomet. Chem. 2008, 57 , 1-116; c) M. G. Voronkov, V. I. Lavrent'yev, Top. Curr. Chem. 1982, 102, 199-236.

[2] K. Pielichowski, J. Njuguna, B. Janowski, J. Pielichowski, Adv. Polym. Sci. 2006, 201, 225-296..

[3] a) E. Markovic, S. Clarke, J. Matisons, G.P. Simon, Macromolecules 2008, 41, 1685-1692; b) C. Zhao, X. Yang, X. Wu, X. Liu, X. Wang, L.Lu, Polym. Bull. 2008, 60, 495- 505 .

[4] S. Bizet, J. Galy, J.F. Gerard, Macromolecules 2006, 39, 2574 -2583.

[5] a) L. Zheng, A.J. Waddon, R.J. Farris, E,B. Coughlin, Macromolecules 2002, 35 , 2375-2379; b) E.T. Kopesky, T.S. Haddad, R.E. Cohen, G.H. McKinley, Macromolecules 2004, 37, 8992- 9004 ; c) K.Y. Pu, B. Zhang, Z. Ma, P. Wang, X.Y.Qi, R.F. Chen, L. H. Wang, Q.-L. Fan, W. Huang, Polymer 2006, 47, 1970 $-1978$

[6] S. Bizet, J. Galy, J.F. Gerard, Polymer 2006, 47, 8219- 8227.

[7] O. García, R. Sastre, I. García-Moreno, V. Martin, A. Costela, J. Phys. Chem. C 2008, 112, 14710-14713.

[8] A. Costela, I. García-Moreno, L. Cerdan, V. Martin, O. Garcia, R. Sastre, $A d v$. Mater. 2009, 21, 4163-4166.

[9] S. Takeda, M. Obara, Appl. Phys. B,2009, 94, 443-450.

[10] a) A. Loudet, K. Burgess, Chem. Rev. 2007, 107, 4891-4932; b) [1] R. Ziessel, G. Ulrich, A. Harriman, New J. Chem. 2007, 31, 496-501; c) [1] F. L. Arbeloa, J. Banuelos, V. Martinez, T. Arbeloa and I. L. Arbeloa, Trends Phys. Chem. 2008, 13, 101-122; d) [1] G. Ulrich, R. Ziessel and A. Harriman, Angew. Chem., Int Ed. 2008, 47, 1184-1201; e) [1] A. C. Benniston and G. Copley, Phys. Chem. Chem. Phys. 2009, 11, 4124-4131.

[11] B. Trastoy, M. E. Pérez-Ojeda, R. Sastre, J. L. Chiara, Chem. Eur. J. 2010, 16, 3833-3841.

[12] J. R. Suárez, B. Trastoy, M. E. Pérez-Ojeda, R. Marín Barrios, J. L. Chiara, $A d v$ Synth. Catal. 2010, 352, 2515-2520.

[13] E. Rikowski, H. C. Marsmann, Polyhedron 1997, 16, 3357-3361.

[14] For recent alternative routes to 2 via nucleophilic substitution with concomitant partial cage rearrangements, see: a) Ge, Z.; Wang, D.; Zhou, Y.; Liu, H.; Liu, S Macromolecules 2009, 42, 2903-2910. b) V. Ervithayasuporn, X. Wang, Y.
Kawakami, Chem. Commun. 2009, 5130-5132. For improved conditions that largely avoid cage rearrangments, see: c) S. Fabritz, D. Heyl, V. Bagutski, M. Empting, E. Rikowski, H. Frauendorf, I. Balog, W.-D. Fessner, J. J. Schneider, O. Avrutina, H. Kolmar, Org. Biomol. Chem. 2010, 8, 2212-2218; d) D. Heyl, E. Rikowski, R. C. Hoffmann, J. J. Schneider, W.-D. Fessner, Chem. Eur. J. 2010, $16,5544-5548$

[15] a) G. Barre, D. Taton, D. Lastecoueres, J.-M.Vincent, J. Am. Chem. Soc. 2004, 126, 7764-7765; b) N. Candelon, D. Lastecoueres, A. K. Diallo, J. Ruiz Aranzaes, D. Astruc, J. M. Vincent, Chem. Commun. 2008, 741-743.

[16] F. López Arbeloa, T. López Arbeloa, I. López Arbeloa, I. García-Moreno, A. Costela, R. Sastre, F. Amat-Guerri, Chem. Phys. 1998, 236, 331-341.

[17] J. Bañuelos, F. López Arbeloa, V. Martínez, T. Arbeloa. F. Amat-Guerri, M. Liras, I. López Arbeloa, Chem. Phys. Lett. 2004, 385, 29-35.

[18] a) S. Mula, A. K. Ray, M. Banerjee, T. Chaudhuri, K. Dasgupta, S. Chattopadhyay, J. Org. Chem. 2008, 73, 2146-2154; b) Q. Zheng, G. Xu, P. N. Prasad, Chem. Eur. J. 2008, 14, 5812-5819; c) T. T. Vu, S. Badré, C. DumasVerdes, J-J. Vachon, C. Julien, P. Audebert, E. Y. Senotrusova, E. Y. Schmidt, B. A. Trofimov, R. B. Pansu, G. Clavier, R. Méallet-Renault, J. Phys. Chem. C 2009, 113, 11844-11855.

[19] a) A. Burghart, H. Kim, M. B. Welch, L. H. Thoresen, J. Reibenspies, K. Burgess, J. Org. Chem. 1999, 64, 7813-7819; b) M. A. H. Alamiry, A. C. Benniston, G. Coeply, K. J. Elliot, A. Harriman, B. Stewart, Y-G. Zhi, Chem. Mater. 2008, 20, 4024-4032; c) F. López Arbeloa, J. Bañuelos, V. Martínez, T. Arbeloa, I. López Arbeloa, Int. Rev. Phys. Chem. 2005, 24, 339-374.

[20] (a) F. López Arbeloa, J. Bañuelos Prieto, I. López Arbeloa, A. Costela, I. García-Moreno, C. Gómez, F. Amat-Guerri, M. Liras, R. Sastre, Photochem. Photobiol. 2003, 78, 30-36; (b) I. García-Moreno, A. Costela, L. Campo, R. Sastre, F. Amat-Guerri, M. Liras, F. López Arbeloa, J. Bañuelos Prieto, I. López Arbeloa, J. Phys. Chem. A 2004, 108, 3315-33232; (c) M. Alvarez, A. Costela, I. García-Moreno, F. Amat-Guerri, M. Liras, R. Sastre, F. López Arbeloa, J. Bañuelos Prieto, I. López Arbeloa, Photochem. Photobiol. Sci. 2008, 7, 802-813.

[21] R. Sastre, V. Martín, L. Garrido, J. L. Chiara, B. Trastoy, O. García, A. Costela, I. García-Moreno, Adv. Func. Mater. 2009, 19, 3307-3316.

[22] L. Cerdan, A. Costela, I. García-Moreno, O. García, R. Sastre, Opt. Express 2010, 18, 10247-10256.

[23] A. Costela, I. García-Moreno, D. del Agua, O. García, R. Sastre, J. Appl. Phys. 2007, 101, 073110-073120.

[24] a) E. G. McRae, M. Kasha, Physical Processes in Radiation Biology, Academic Press, New York, 1964; b) J. E. Selwyn, J. I. Steinfeld, J. Phys. Chem. 1972, 76, $762-774$.

[25] a) F: Bergström, I. Mikhalyov, P. Hagglöf, R. Wortmann, T. Ny, L. B-A. Johansson, J. Am. Chem. Soc. 2002, 124, 196-204; b) D. Tleugabulova, Z. Zhang, J. D. Brennan, J. Phys. Chem. B 2002, 106, 13133-13138; c) M. Bröring, R. Krüger, S. Link, C. Kleeberg, S. Köhler, X. Xie, B. Ventura, L. Flamigni, Chem. Eur. J. 2008, 14, 2976-2983.

[26] A. C. Benniston, G. Copley, A. Harriman, D. Howgegeo, R. W. Harrington, W. Clegg, J. Org. Chem. 2010, 75, 2018-2027.

[27] I. López Arbeloa, J. Chem. Soc. 1981, 77, 1725-1733.

[28] K. H. Drexhage, in Dye Lasers (Ed: F. P: Shäfer) Springer-Verlag, Berlin, 1990, chap. 5, pp. 155-200.

[29] S. Punna, M. G. Finn, Synlett 2004, 99-100.

[30] A. B. Pangborn, M. A. Giardello, R. H. Grubbs, R. K. Rosen, F. J. Timmers, Organometallics 1996, 15, 1518-1520.

[31] a) G. Ulrich, R. Ziessel, J. Org. Chem. 2004, 69, 2070-2083; b) V. A. Azov, A Schlegel, F. Diederich, Angew. Chem. Int. Ed. 2005, 44, 4635-4638.

[32] M. Álvarez, F. Amat-Guerri, A. Costela, I. García-Moreno, C. Gómez, M. Liras, R. Sastre, Appl. Phys. B. 2005, 80, 993-1006.

[33] A. Costela, I. García-Moreno, D. del Agua, O. García, R. Sastre, J. Appl. Phys., 2007, 101, 073110-11 
Received: ((will be filled in by the editorial staff))

Revised: ((will be filled in by the editorial staff))

Published online: ((will be filled in by the editorial staff))

$\longrightarrow$ 


\section{Entry for the Table of Contents}

Hybrid dyes

M. E. Pérez-Ojeda, B. Trastoy, I. López-Arbeloa, *J. Bañuelos, A. Costela, I. García-Moreno, * and J. L. Chiara*............ Page - Page

Click Assembly of DyeFunctionalized

Octasilsesquioxanes for Highly Efficient and Photostable Photonic Systems
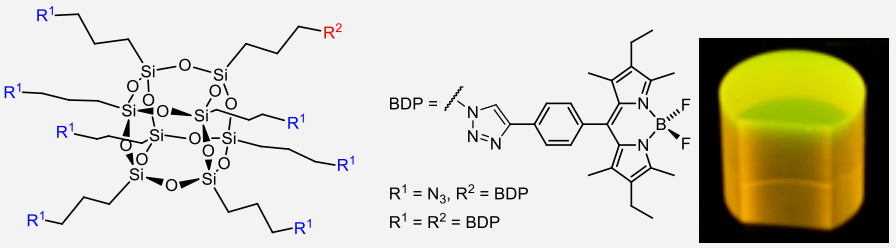

Fluorescently labeled mono- or octasusbtituted octasilsesquioxanes can

Attachment to the inorganic core significantly improves dye laser performance in both liquid phase and solid matrices. corresponding octa-azido

silsesquioxane using click chemistry. 


\section{Supporting Information}

Click Assembly of Dye-Functionalized Octasilsesquioxanes for Highly Efficient and Photostable Photonic Systems

M. Eugenia Pérez-Ojeda, Beatriz Trastoy, Íñigo López-Arbeloa, * Jorge

Bañuelos, Ángel Costela, Inmaculada García-Moreno, ${ }^{*}$ and Jose Luis

Chiara* 
Table S1. Photophysical properties of compounds 3, 6 and 5 in six representative solvents of apolar (c-hexane), polar (ethyl acetate and acetone) and polar/protic (ethanol, methanol, and trifluoroethanol) environments. Absorption $\left(\lambda_{\text {abs }}\right)$ and fluorescence $\left(\lambda_{\text {flu }}\right)$ wavelength, molar absorption coefficient $\left(\varepsilon_{\max }\right)$, fluorescence quantum yield $(\phi)$ and lifetime $(\tau)$, radiative $\left(\mathrm{k}_{\mathrm{fl}}\right)$ and non-radiative $\left(\mathrm{k}_{\mathrm{nr}}\right)$ deactivation rate constants, and Stokes shift $\left(\Delta v_{\mathrm{St}}\right)$. The corresponding data of the commercial PM567 dye are also included for comparison.

\begin{tabular}{|c|c|c|c|c|c|c|c|c|}
\hline Solvent & $\begin{array}{c}\lambda_{\text {abs }} \\
( \pm 0.5 \mathrm{~nm})\end{array}$ & $\begin{array}{c}\varepsilon_{\max } \\
\left(10^{4} \mathrm{M}^{-1} \mathrm{~cm}^{-1}\right)\end{array}$ & $\begin{array}{c}\lambda_{\text {flu }} \\
( \pm 0.5 \mathrm{~nm})\end{array}$ & $\begin{array}{c}\phi \\
( \pm 0.05)\end{array}$ & $\begin{array}{c}\tau \\
( \pm 0.05 \mathrm{~ns})\end{array}$ & $\begin{array}{c}\mathrm{k}_{\mathrm{fl}} \\
\left(10^{8} \mathrm{~s}^{-1}\right) \\
\end{array}$ & $\begin{array}{c}\mathrm{k}_{\mathrm{nr}} \\
\left(10^{8} \mathrm{~s}^{-1}\right)\end{array}$ & $\begin{array}{r}\Delta v_{\mathrm{St}} \\
\left(\mathrm{cm}^{-1}\right)\end{array}$ \\
\hline \multicolumn{9}{|l|}{ compound 3} \\
\hline F3-ethanol & 523.0 & 7.0 & 538.5 & 0.71 & 5.82 & 1.22 & 0.50 & 560 \\
\hline methanol & 523.5 & 7.7 & 539.5 & 0.66 & 4.50 & 1.46 & 0.75 & 565 \\
\hline ethanol & 524.5 & 7.8 & 540.0 & 0.68 & 4.59 & 1.48 & 0.69 & 540 \\
\hline acetone & 523.5 & 7.8 & 539.5 & 0.64 & 4.12 & 1.55 & 0.87 & 565 \\
\hline ethyl acetate & 524.0 & 8.0 & 539.5 & 0.70 & 4.40 & 1.59 & 0.68 & 540 \\
\hline c-hexane & 527.5 & 8.5 & 542.0 & 0.54 & 2.96 & 1.82 & 1.55 & 515 \\
\hline \multicolumn{9}{|l|}{ compound $\mathbf{6}$} \\
\hline F3-ethanol & 522.5 & 6.1 & 538.0 & 0.78 & 6.24 & 1.25 & 0.35 & 550 \\
\hline methanol & 522.5 & 6.8 & 538.0 & 0.73 & 4.90 & 1.49 & 0.55 & 545 \\
\hline ethanol & 523.5 & 7.0 & 538.0 & 0.78 & 4.92 & 1.58 & 0.44 & 520 \\
\hline acetone & 522.5 & 7.0 & 537.5 & 0.71 & 4.60 & 1.54 & 0.63 & 520 \\
\hline ethyl acetate & 522.5 & 7.1 & 537.0 & 0.80 & 4.83 & 1.65 & 0.41 & 510 \\
\hline c-hexane & 526.0 & 8.1 & 540.0 & 0.67 & 3.74 & 1.79 & 0.88 & 480 \\
\hline \multicolumn{9}{|l|}{ compound 5} \\
\hline F3-ethanol & 523.0 & 5.1 & 537.5 & 0.56 & 6.21 & 0.90 & 0.71 & 525 \\
\hline methanol & 523.0 & 5.4 & 537.5 & 0.54 & 4.86 & 1.11 & 0.94 & 510 \\
\hline ethanol & 524.0 & 5.9 & 538.0 & 0.59 & 4.93 & 1.19 & 0.83 & 500 \\
\hline acetone & 522.5 & 5.8 & 537.0 & 0.56 & 4.62 & 1.21 & 0.95 & 515 \\
\hline ethyl acetate & 523.0 & 5.8 & 537.0 & 0.64 & 4.83 & 1.32 & 0.74 & 510 \\
\hline c-hexane & 526.0 & 5.8 & 540.0 & 0.60 & 3.86 & 1.55 & 1.03 & 485 \\
\hline \multicolumn{9}{|l|}{ PM567 } \\
\hline F3-ethanol & 515.5 & 7.1 & 535.0 & 0.97 & 6.94 & 1.39 & 0.04 & 705 \\
\hline methanol & 516.0 & 7.9 & 531.5 & 0.91 & 6.10 & 1.49 & 0.14 & 560 \\
\hline ethanol & 517.5 & 8.1 & 532.5 & 0.84 & 6.09 & 1.38 & 0.26 & 535 \\
\hline acetone & 516.0 & 8.0 & 532.0 & 0.85 & 5.92 & 1.43 & 0.25 & 580 \\
\hline ethyl acetate & 516.5 & 8.0 & 531.5 & 0.80 & 5.78 & 1.38 & 0.34 & 550 \\
\hline c-hexane & 522.5 & 9.3 & 537.0 & 0.70 & 5.60 & 1.25 & 0.53 & 525 \\
\hline
\end{tabular}


Table S2. Photophysical properties of compound 4 in ethyl acetate, acetone and 2,2,2trifluoroethanol (compound $\mathbf{4}$ was not soluble in the other solvents included in Table S1).

\begin{tabular}{|c|c|c|c|c|c|c|}
\hline Solvent & $\begin{array}{c}\lambda_{\mathrm{abs}} \\
( \pm 0.5 \mathrm{~nm})\end{array}$ & $\begin{array}{c}\varepsilon_{\max } \\
\left(10^{4} \mathrm{M}^{-1} \mathrm{~cm}^{-1}\right)\end{array}$ & $\begin{array}{c}\lambda_{\text {flu }} \\
( \pm 0.5 \mathrm{~nm})\end{array}$ & $\begin{array}{c}\phi \\
( \pm 0.05)\end{array}$ & $\begin{array}{c}\tau \\
( \pm 0.05 \mathrm{~ns})\end{array}$ & $\begin{array}{r}\Delta v_{\mathrm{St}} \\
\left(\mathrm{cm}^{-1}\right)\end{array}$ \\
\hline \multirow[t]{3}{*}{$\mathrm{CF}_{3} \mathrm{CH}_{2} \mathrm{OH}$} & 524.0 & 28.0 & 544.5 & 0.02 & $4.56(1 \%)$ & 725 \\
\hline & & & & & $0.70(30 \%)$ & \\
\hline & & & & & $0.13(69 \%)$ & \\
\hline \multirow[t]{3}{*}{ acetone } & 523.0 & 38.0 & 545.0 & 0.14 & $3.41(37 \%)$ & 770 \\
\hline & & & & & $1.16(27 \%)$ & \\
\hline & & & & & $0.12(36 \%)$ & \\
\hline \multirow[t]{3}{*}{ ethyl acetate } & 524.0 & 35.0 & 544.5 & 0.31 & $5.03(53 \%)$ & 730 \\
\hline & & & & & $1.99(25 \%)$ & \\
\hline & & & & & $0.19(22 \%)$ & \\
\hline
\end{tabular}




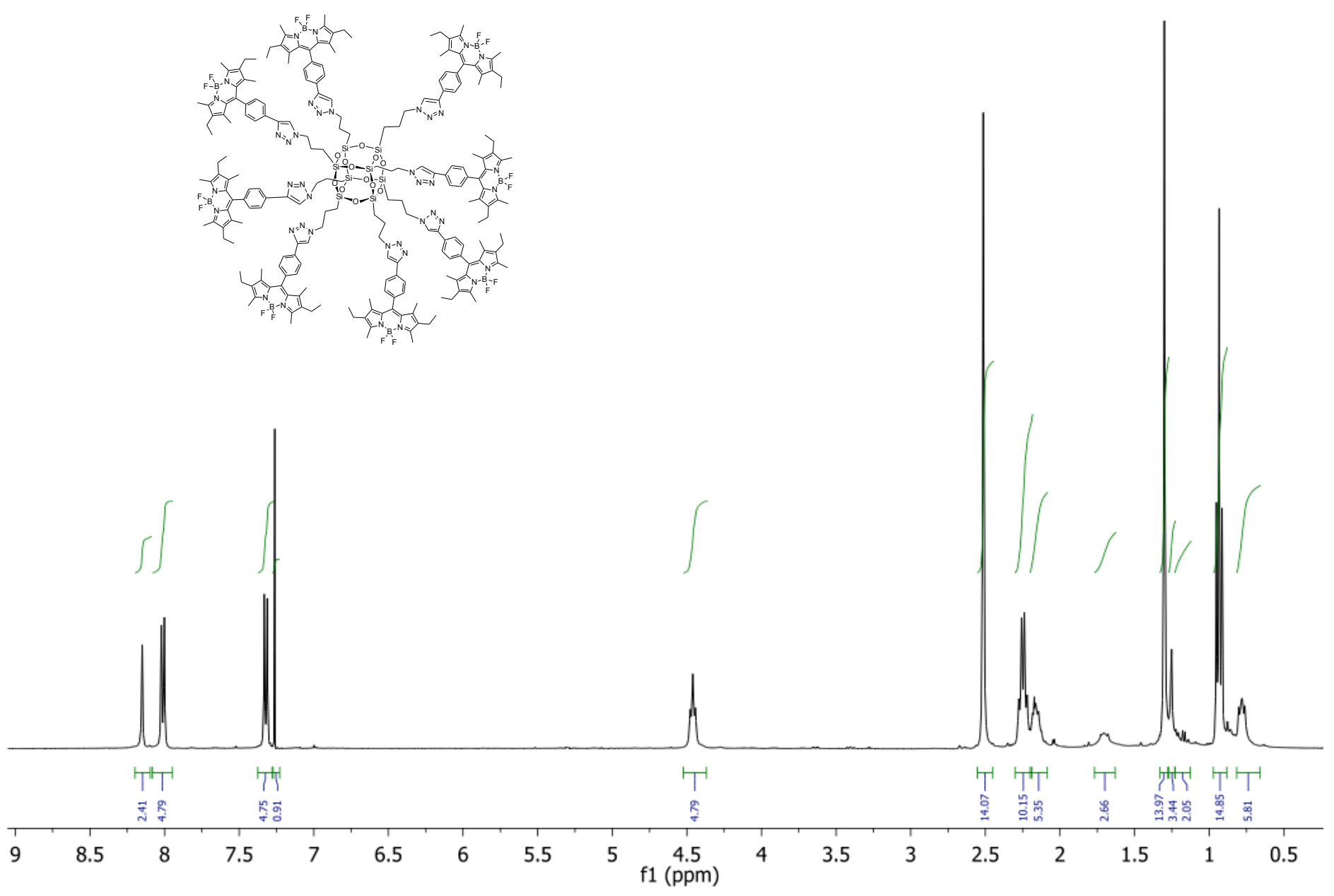

${ }^{1} \mathrm{H}$ NMR $\left(\mathrm{CDCl}_{3}, 400 \mathrm{MHz}\right)$ spectrum of compound 4 

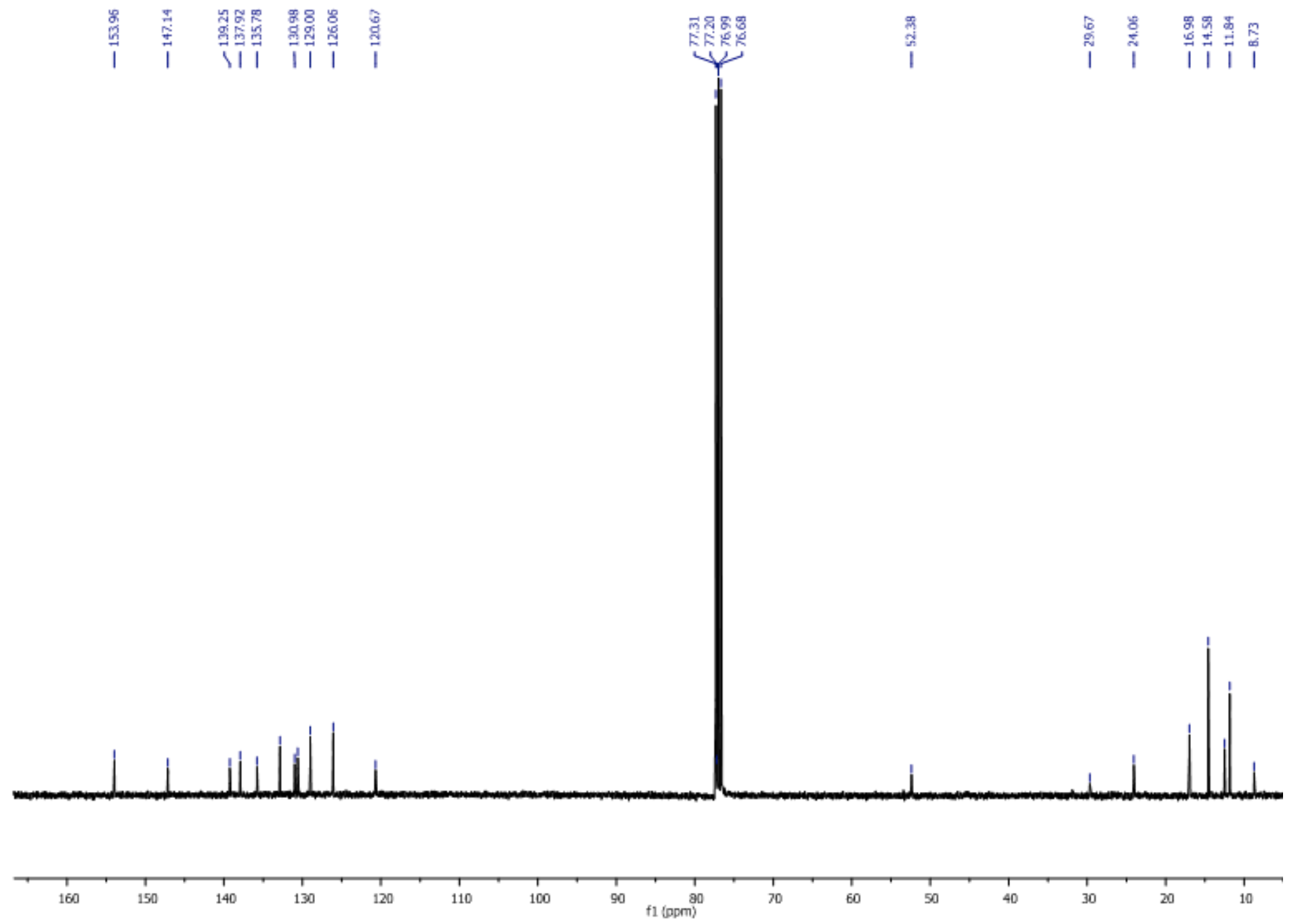

${ }^{13} \mathrm{C} \mathrm{NMR}\left(\mathrm{CDCl}_{3}, 100 \mathrm{MHz}\right)$ spectrum of compound 4 


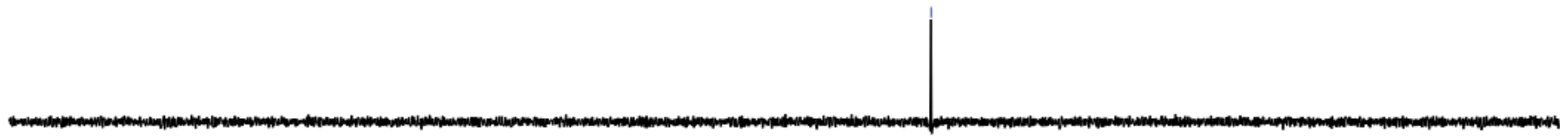

$\begin{array}{llllllllllllllllllllllll}-10 & -15 & -20 & -25 & -30 & -35 & -40 & -45 & -50 & -55 & -60 & -65 & -70 & -75 & -80 & -85 & -90 & -95 & -100 & -105\end{array}$

${ }^{29} \mathrm{Si} \mathrm{NMR}\left(\mathrm{CDCl}_{3}, 79.5 \mathrm{MHz}\right)$ spectrum of compound 4 

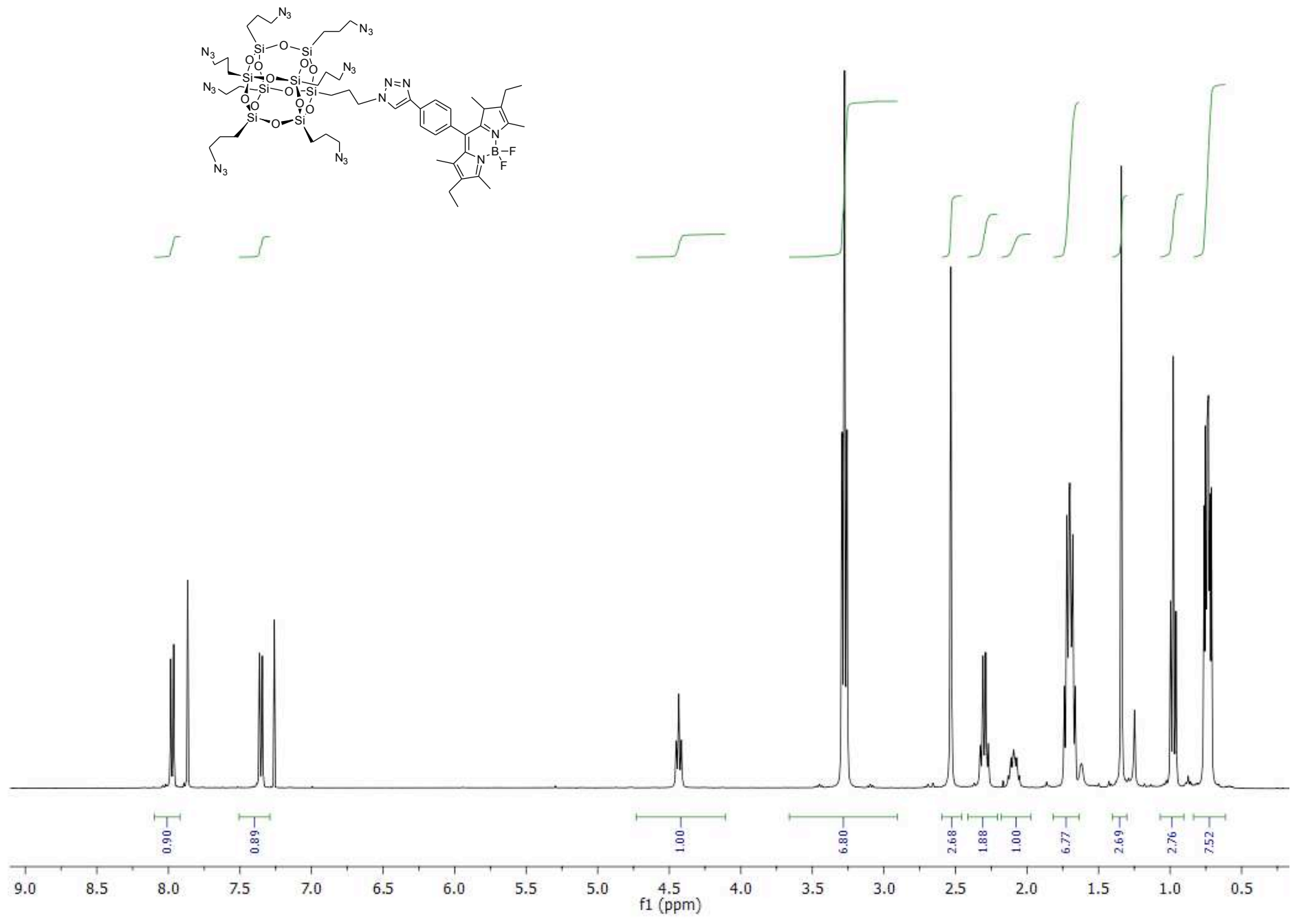

${ }^{1} \mathrm{H} \mathrm{NMR}\left(\mathrm{CDCl}_{3}, 400 \mathrm{MHz}\right)$ spectrum of compound $\mathbf{5}$ 

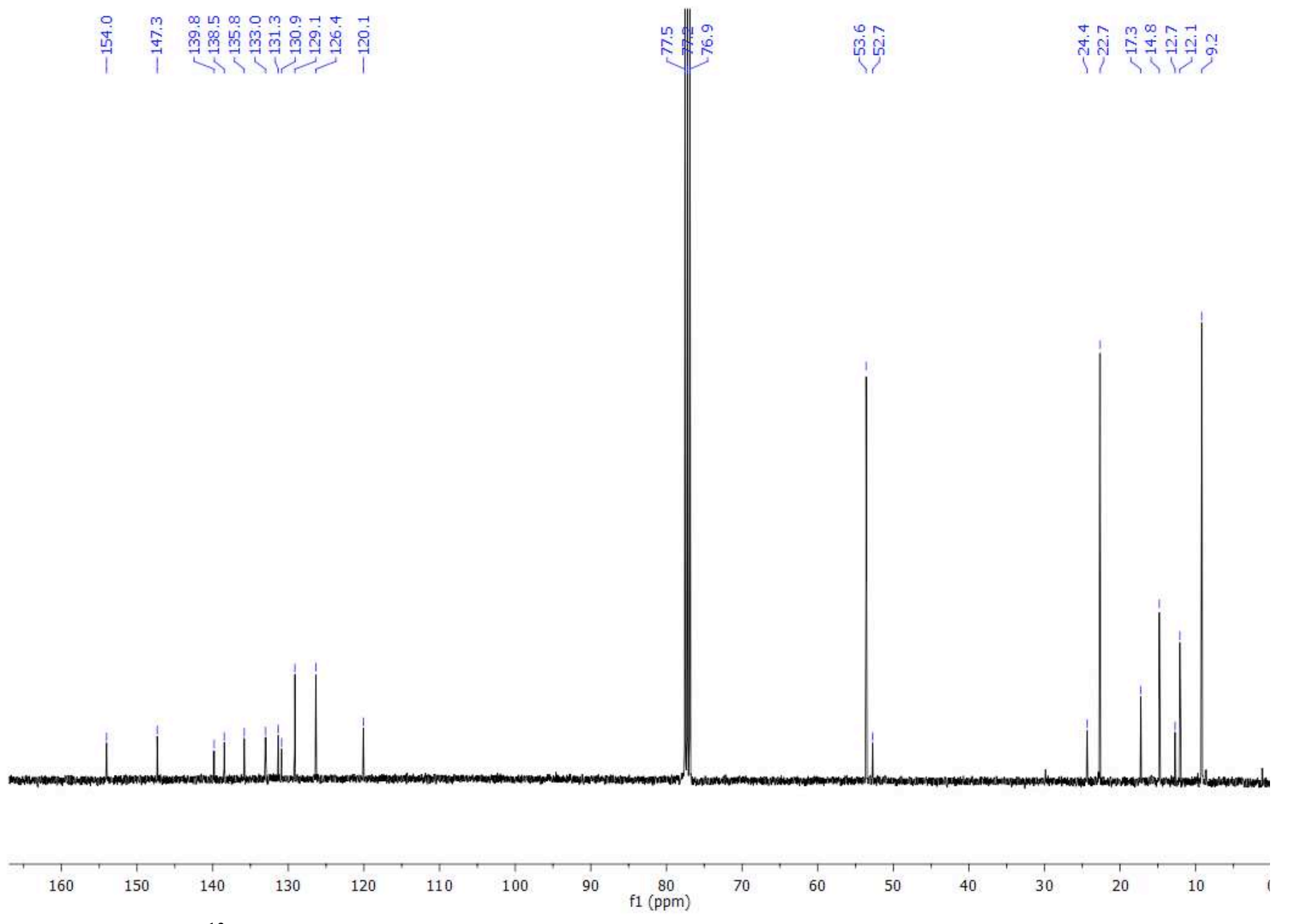

${ }^{13} \mathrm{C}$ NMR $\left(\mathrm{CDCl}_{3}, 100 \mathrm{MHz}\right)$ spectrum of compound 5 

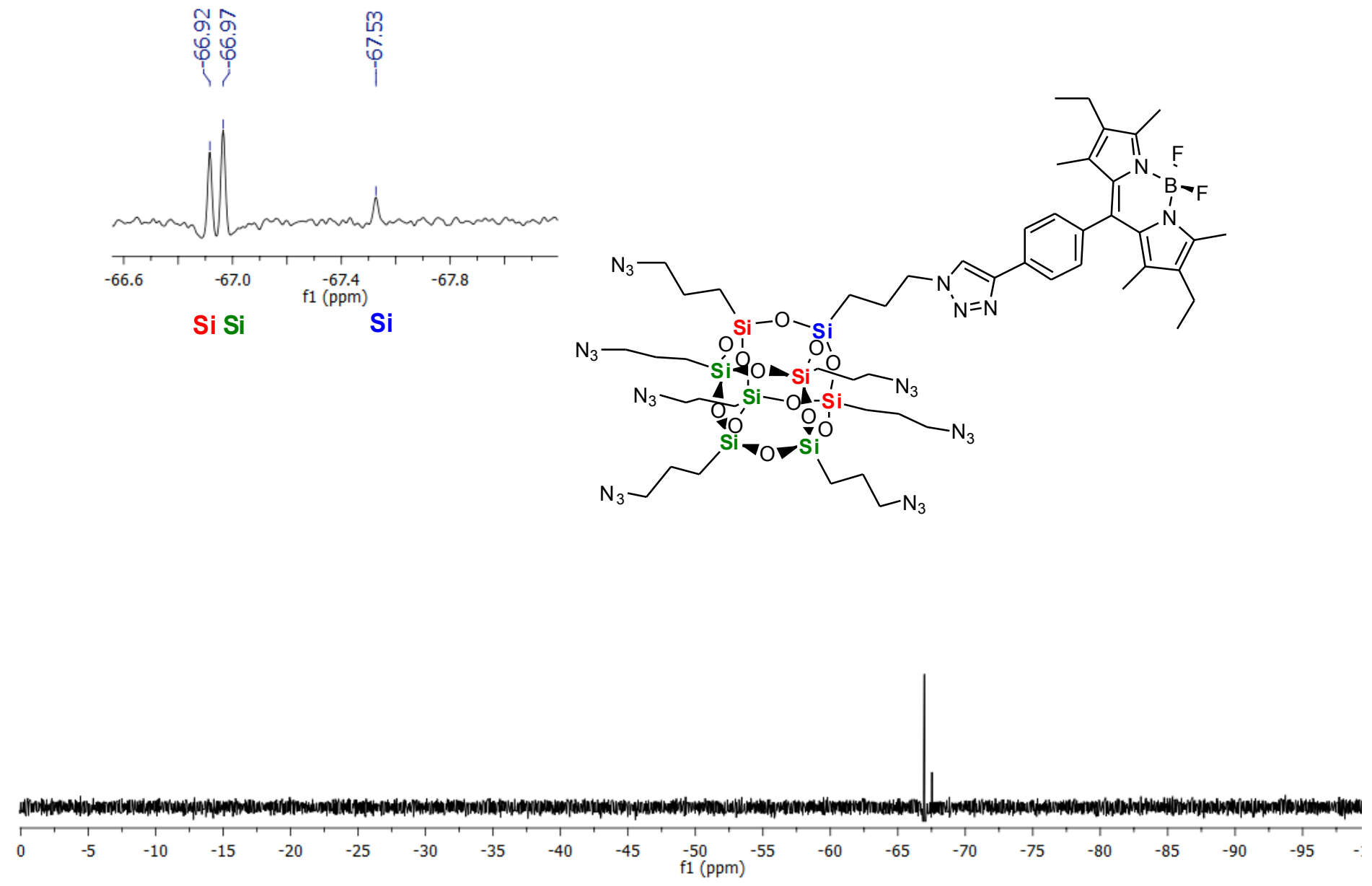

${ }^{29} \mathrm{Si} \mathrm{NMR}\left(\mathrm{CDCl}_{3}, 79.5 \mathrm{MHz}\right)$ spectrum of compound $\mathbf{5}$ 


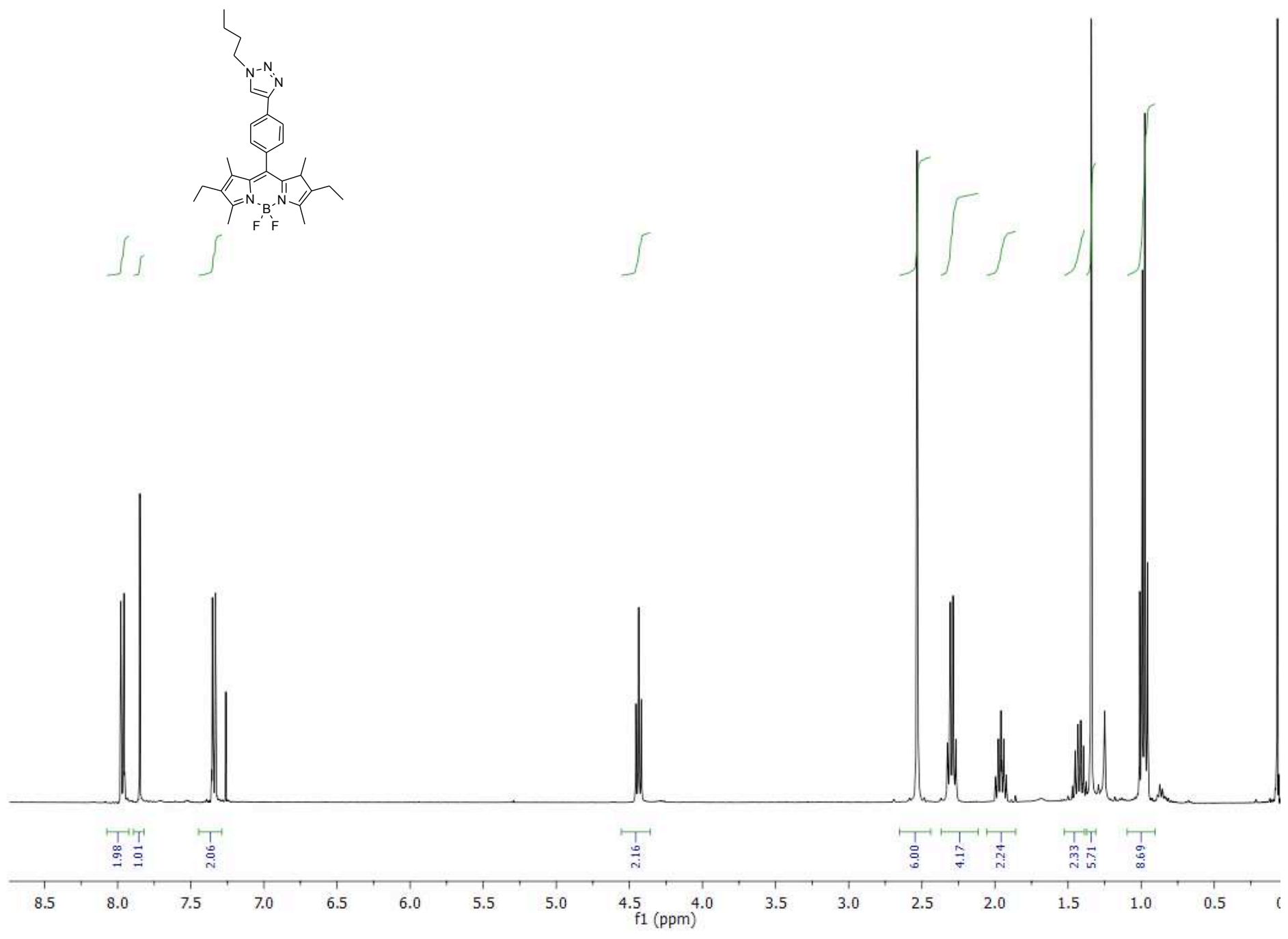

${ }^{1} \mathrm{H} \mathrm{NMR}\left(\mathrm{CDCl}_{3}, 400 \mathrm{MHz}\right)$ spectrum of compound 6 

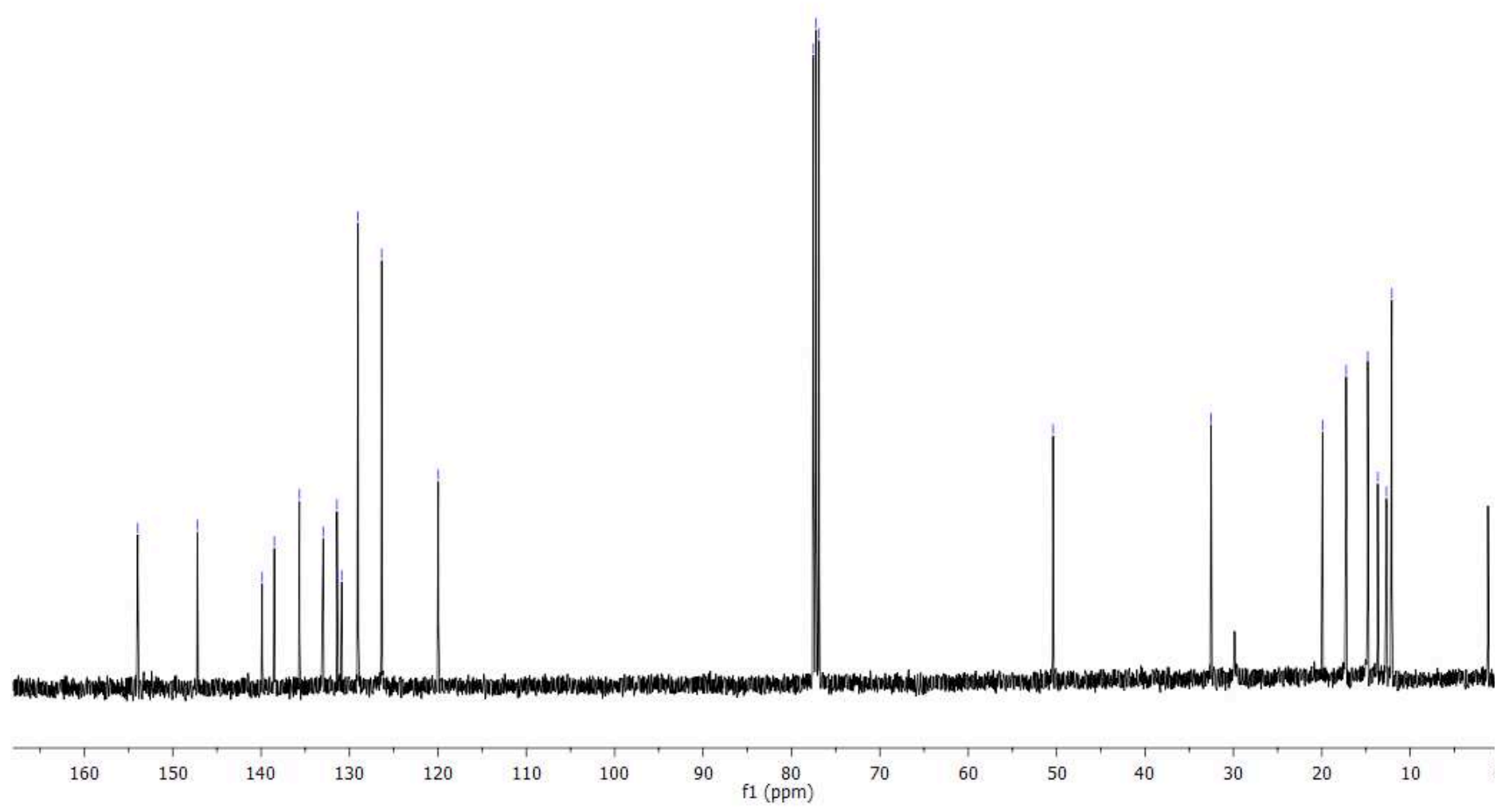

${ }^{13} \mathrm{C} \mathrm{NMR}\left(\mathrm{CDCl}_{3}, 100 \mathrm{MHz}\right)$ spectrum of compound $\mathbf{6}$ 